\title{
Rig-G is a growth inhibitory factor of lung cancer cells that suppresses STAT3 and NF-KB
}

\author{
Dong Li ${ }^{1, *}$, Junjun Sun ${ }^{1, *}$, Wenfang Liu' ${ }^{2, *}$, Xuan Wang ${ }^{3}$, Robert Bals ${ }^{4}$, Junlu Wu ${ }^{1}$, \\ Wenqiang Quan ${ }^{1}$, Yiwen Yao ${ }^{1}$, Yu Zhang ${ }^{1}$, Hong Zhou ${ }^{1}$, Kaiyin Wu ${ }^{5}$ \\ ${ }^{1}$ Department of Clinical Laboratory, Shanghai Tongji Hospital, Tongji University School of Medicine, 200065 Shanghai, China \\ ${ }^{2}$ Department of General Surgery, Shanghai Tongji Hospital, Tongji University School of Medicine, 200065 Shanghai, China \\ ${ }^{3}$ Department of Pharmacy, Putuo People's Hospital, 200060 Shanghai, China \\ ${ }^{4}$ Department of Internal Medicine V - Pulmonology, Allergology, Respiratory Intensive Care Medicine, Saarland University \\ Hospital, 66424 Homburg, Germany \\ ${ }^{5}$ Institute of Pathology, Charité Medical University, 10117 Berlin, Germany \\ "These authors contributed equally as first authors \\ Correspondence to: Dong Li, email: 186ld@163.com
}

Keywords: Rig-G, lung cancer, growth inhibition, NF- $\kappa B$, STAT3

Received: February 25, $2016 \quad$ Accepted: August 24, 2016

Published: September 01, 2016

\section{ABSTRACT}

The expression of the retinoic acid-induced G (Rig-G) gene, an all trans retinoic acid (ATRA)-inducible gene, was observed in multiple cancer cells, including lung cancer cells. However, whether Rig-G is a tumor suppressor in lung cancer is unknown. Here, we found that ectopic expression of Rig-G can lead to a significant decrease in proliferation of lung cancer cells, resulting in an inhibition of tumor growth. Rig-G knockdown results in a modest increase in cell proliferation, as well as confers an increase in colony formation. Furthermore, transcriptome and pathway analyses of cancer cells revealed a fundamental impact of Rig-G on various growth signaling pathways, including the NF-KB pathway. Rig-G inhibits NF-KB activity by suppressing STAT3 in lung cancer cells. The downregulation of miR21 and miR181b-1 and subsequent activation of PTEN/Akt and CYLD/IKB signaling axis leading to decreased NF-KB activity required to maintain the tumor-inhibiting effect of Rig-G.. Our findings contribute to a better understanding of the antitumor effect mechanism of Rig-G, as well as offer a novel strategy for lung cancer therapy.

\section{INTRODUCTION}

Lung cancer currently remains the leading cause of death from cancer in the world [1]. Among lung cancers, non-small cell lung cancer (NSCLC) constitutes $80 \%$ of all lung cancers $[2,3]$. Despite advances in early detection and standard treatment, lung cancer is often diagnosed at an advanced stage and has poor prognosis [4]. Therefore, prevention and treatment of lung cancer are the focus of intensive current research [5].

Retinoic acid-induced gene $\mathrm{G}$ (Rig-G) is an all trans retinoic acid (ATRA)-inducible gene, previously identified from an acute promyelocytic leukemia (APL) cell line NB4 by using the technique of differential Display PCR $[6,7]$. Rig-G gene expression can be induced not only in NB4 cells but also in various types of solid carcinoma cells, including head and neck squamous carcinoma cells, NSCLC H460 and A549 cells, cervical carcinoma HeLa cells, and epithelium-like WISH cells [8]. Studies have shown that Rig-G is a growth inhibitor for leukemia cells, whose antiproliferative effect was induced via the upregulation of $\mathrm{p} 21$ and $\mathrm{p} 27$, two negative regulators of cell cycle progression [8]. Rig-G blocks nuclear export of p27 and its subsequent proteolysis by interfering with the normal function of JAB1, a co-activator of the AP1 transcription factor. This event then mediates the nuclear export of p27 and facilitates p27 to degrade via ubiquitin/proteasome pathway in cytoplasm, finally increasing p27 protein levels and inhibiting cell growth [8]. Rig-G also upregulates p21 at the transcriptional level by decreasing c-Myc expression, thereby inhibiting cell proliferation and facilitating cell differentiation [8].

$\mathrm{NF}-\mathrm{\kappa B}$ and STAT3 play pivotal roles in various aspects of the tumorigenic process in several cancer entities, including colon, lung cancer, and hepatocellular carcinoma [9-11]. These are powerful activators of malignancy and are prerequisites for the expression of a variety of target genes that 
are important for cell proliferation, survival, angiogenesis, invasion, and metastasis $[12,13]$. On the contrary, in immune cells, NF- $\kappa$ B and STAT3 control the expression of other cytokines and inflammatory/immune mediators that mediate $\mathrm{NF}-\kappa \mathrm{B}$ and STAT3 activation in cancer cells, including IL-1, IL-6, and TNF $\alpha$ [14]. The interaction of NF- $\kappa$ B and STAT3 has been found in some human cancers, including colon, gastric, and liver $[12,15,16]$. NF- $\mathrm{B}$ physically interacts with STAT3, which may result in either specific transcriptional synergy or repression of NF- $\kappa$ B/STAT3 regulated genes $[12,16]$. STAT3 may interact with RelA/p65 in the nucleus and prolong the presence of active NF- $\mathrm{KB}$ in the nucleus [16]. STAT3 activation of miR-21 and miR-181b-1 has dramatic effects on NF- $\kappa \mathrm{B}$ activity in the tumor cells [17]. It was also observed that STAT3 inactivation may be responsible for decreased NF- $\kappa B$ activity [17]. Despite these versatile interactions, NF- $\kappa \mathrm{B}$ and STAT3 cooperate to promote the development and progression of tumors $[15,16]$.

The aim of the present study was to determine whether overexpression of Rig-G in lung cancer cells alters its growth and which growth inhibition signaling pathways in cancer cells are involved. Here we use an inducible Rig-G expression model to study the effects of Rig-G in the lung cancer cell, and identify the underlying molecular mechanisms.

\section{RESULTS}

\section{ATRA upregulates Rig-G expression and inhibits the growth of lung cancer cells in vitro}

In our previous work, we showed that Rig-G, whose expression is triggered by ATRA, plays an important role in leukemia cell growth inhibition [8]. To assess whether ATRA-induced Rig-G induction and cell growth inhibition are relevant in lung cancer cells, three NSCLC cell lines were used to detect the induction of Rig-G at the protein and mRNA levels. A previous report showed that the peak plasma levels of a single oral dose of 45 $\mathrm{mg} / \mathrm{m}^{2}$ that is administered to patients is $1 \mu \mathrm{M}$ ATRA; therefore, $1 \mu \mathrm{M}$ ATRA was used in the present study [18]. Western blot analysis showed that treatment with $1 \mu \mathrm{M}$ ATRA for $96 \mathrm{~h}$ significantly increased the expression of Rig-G in A549, H1792, and Calu-1 cells (Figure 1A). The levels of Rig-G mRNA were perfectly consistent
A

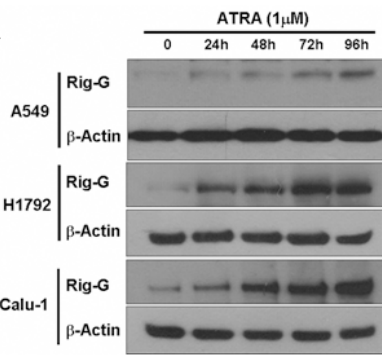

B
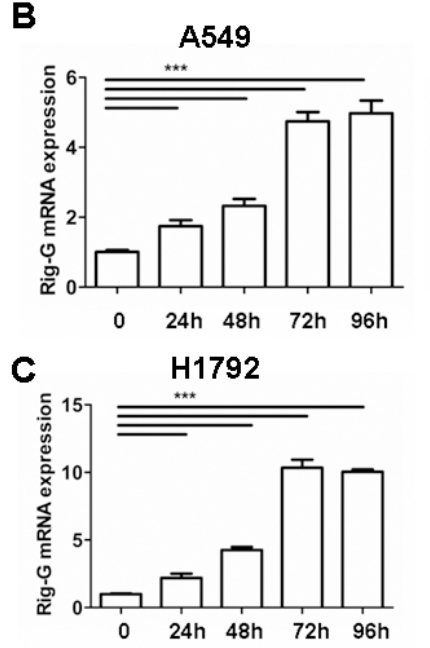

D

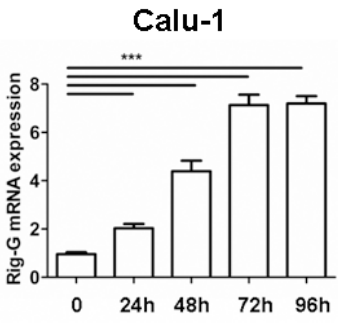

E

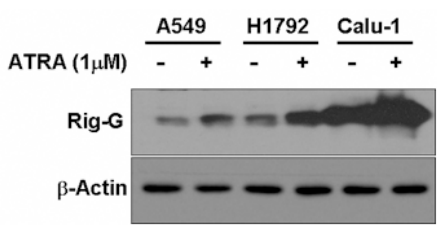

$\mathbf{F}$

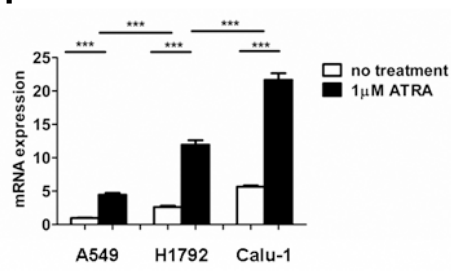

G
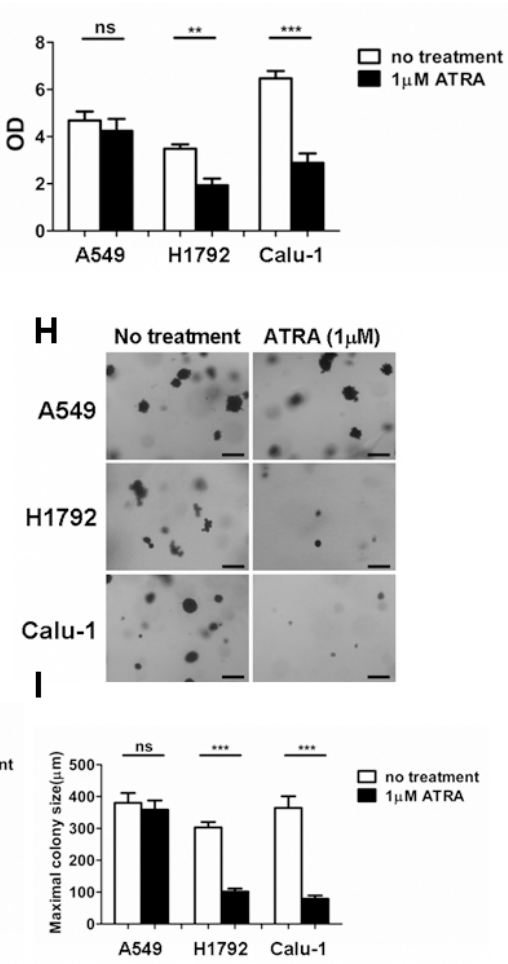

Figure 1: ATRA upregulates Rig-G expression and inhibits the growth of lung cancer cells in vitro. A-F. Total protein and RNA from A549, H1792, and Calu-1 cells were isolated after treatment with $1 \mu \mathrm{M}$ of ATRA for $96 \mathrm{~h}$. The expression of Rig-G protein was analyzed by western blot (A and E). The expression of Rig-G mRNA in three NSCLC cell lines (B-D and F) was measured by real-time PCR. The results are expressed as the mean \pm SEM, ${ }^{* * *} p<0.001$ G. Lung cancer cell lines A549, H1792, and Calu- 1 were treated with $1 \mu \mathrm{m}$ ATRA for $96 \mathrm{~h}$, after which cell proliferation was measured by ELISA (BrdU labeling) analysis. The results are expressed as the mean \pm SEM, $* * p<$ $0.01 ;{ }^{* *} p<0.001$; n.s., not significant. H. A549, H1792, and Calu-1 cells were treated with $1 \mu \mathrm{m}$ ATRA and assessed for growth in soft agar by using the anchorage-independent colony formation assay. Scale bars $=500 \mu \mathrm{m}$. I. The maximum colony size of A549, H1792, and Calu-1 cells in a soft-agar assay was determined. The results are expressed as the mean $\pm \mathrm{SEM}, * * * p<0.001$; n.s., not significant. 
with the kinetics of Rig-G protein expression (Figure 1B, 1C, 1D). Interestingly, Rig-G expression in A549 cells was significantly lower than that in Calu-1 and H1792 cells (Figure 1E, 1F). The cell lines were treated for $96 \mathrm{~h}$ and a BrdU ELISA cell proliferation assay was subsequently performed. Growth inhibition of Calu-1 and H1792 cells significantly increased after treatment with ATRA, whereas A549 cells were less sensitive to ATRA (Figure 1G). An anchorage-independent colony formation assay was conducted to determine whether ATRA reduces the ability of soft agar colony formation in Calu-1, A549, and H1792 cells. ATRA significantly inhibited the ability of Calu-1 and H1792 cells to grow on soft agar, whereas minimal inhibition was observed after ATRA treatment of A549 cells (Figure 1H, 1I). These results were in agreement to those obtained by measuring cell proliferation. Collectively, these results indicate that ATRA stimulates Rig-G expression and inhibits lung cancer cell growth in a cell-dependent manner.

\section{Rig-G inhibits lung cancer cell growth and impairs tumor development in xenograft models}

As ATRA treatment results in a significant increase in Rig-G expression and inhibition of lung cancer cell growth, we hypothesized that Rig-G induces growth inhibition of lung cancer cells. In accord with this idea, Calu-1, A549, and H1792 cells stably expressing Rig-G were generated using the Tet-On expression system. In the presence of doxycycline (Dox), the induced expression of Rig-G in Tet-On Rig-G stably expressing cell lines was confirmed by western blot analysis (Figure 2A). Empty vector pTRE was used as control. The upregulation of Rig-G in Tet-On Rig-G stably expressing cell lines resulted in a very low background of Rig-G expression in control cells (Figure 2A). As expected, the overexpression of Rig-G in Calu-1 and $\mathrm{H} 1792$ cells resulted in a significant inhibition of cell growth after the addition of Dox (Figure 2B). Analysis of anchorage-independent colony formation further showed that cellular expression of Rig-G significantly decreased the ability of lung cancer cell lines Calu-1 and H1792 to grow on soft agar (Figure 2C, 2D). Strikingly, A549 cells, which are resistant to ATRA, overexpressed Rig-G that strongly inhibited cell growth as well as the ability to form colonies in soft agar (Figure 2B, 2C, 2D). In addition, we also examined whether the loss of Rig-G affected the growth of lung tumor cells. We inhibited Rig-G expression by transfection with Rig-G shRNA in tumor cells (Figure 3A). In three cell lines, inhibition of Rig-G results in a modest increase in cell proliferation, as well as confers an increase in colony formation (Figure 3B, 3C, 3D). Nude mice were injected subcutaneously with A549 cells carrying a regulated Rig-G expression cassette or control cassette to generate tumors. Tumor-bearing animals were fed Dox or water to regulate Rig-G expression in mice xenografts (Figure 4A). Expression of Rig-G significantly suppressed
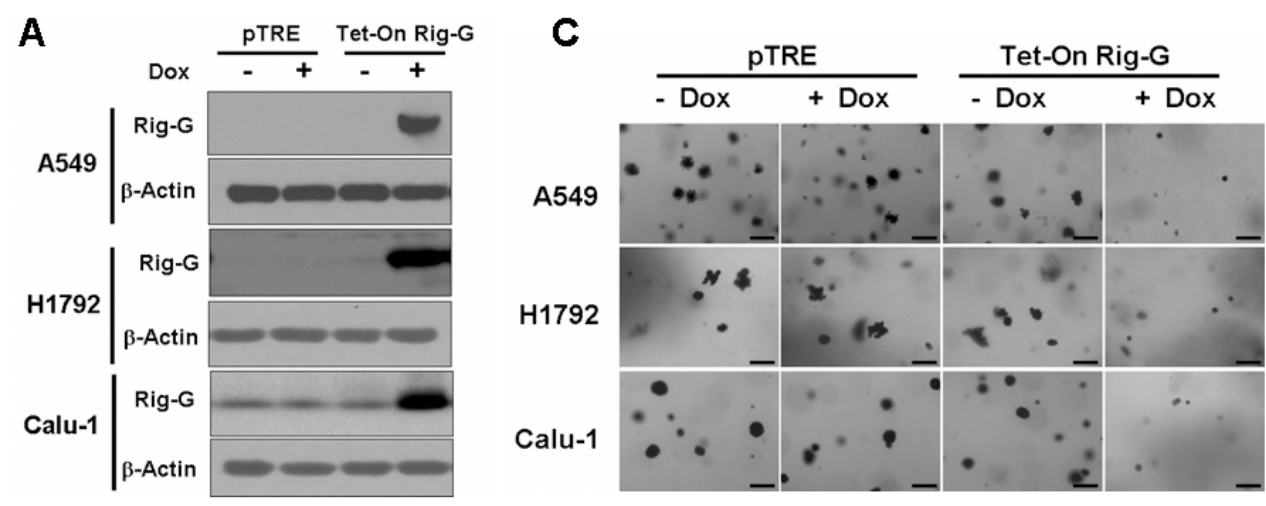

B

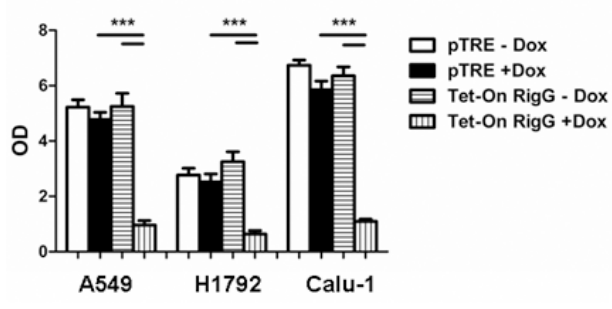

$\mathbf{D}$

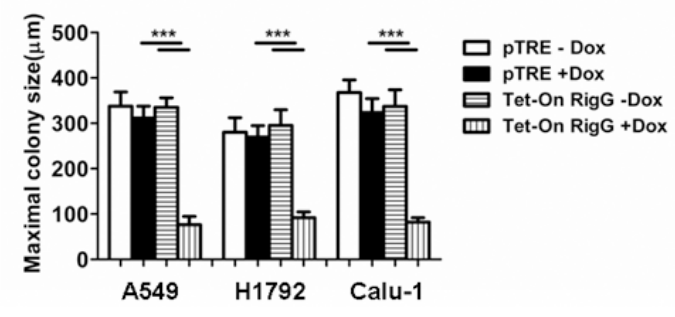

Figure 2: Rig-G inhibits lung cancer cell growth. A. The lung cancer cell (A549, H1792, and Calu-1) sublines pTRE and Tet-on Rig-G were cultured, respectively, in the presence or absence of Dox $(2 \mu \mathrm{g} / \mathrm{mL})$ for $24 \mathrm{~h}$. The expression of Rig-G protein was detected by immunoblotting. B. The proliferation of the indicated cells was measured by ELISA (BrdU labeling) analysis. The results are expressed as the mean \pm SEM, $* * * p<0.001$. C. The growth of the indicated cells in soft agar was assessed by using an anchorage-independent colony formation assay. Scale bars $=500 \mu \mathrm{m}$. D. The maximum colony size of A549, H1792, and Calu-1 cells in a soft-agar assay was determined. The results are expressed as the mean $\pm \mathrm{SEM}, * * * p<0.001$. 
tumor growth, as a reduction in tumor size was observed relative to that in the control (Figure 4B). The proliferation of tumor cells was then examined via immunohistochemical staining for Ki-67. Consistent with the observed changes in the xenografts, the number of cells expressing Ki-67 was significantly lower in tumors from mice showing Rig-G overexpression compared to mice showing a low level of Rig-G expression (Figure 4C, 4D). Next, to investigate whether Rig-G has an impact on apoptosis in tumor cells, apoptotic cells were identified by in situ terminal-transferase dUTP-mediated nick end-labeling (TUNEL) assay, which showed no significant differences between groups (Figure $4 \mathrm{E})$. These results indicate that Rig-G appears to play a critical role in the inhibition of lung tumor growth, most likely through inhibiting the proliferation of malignant cells, without affecting rate of apoptosis.

A

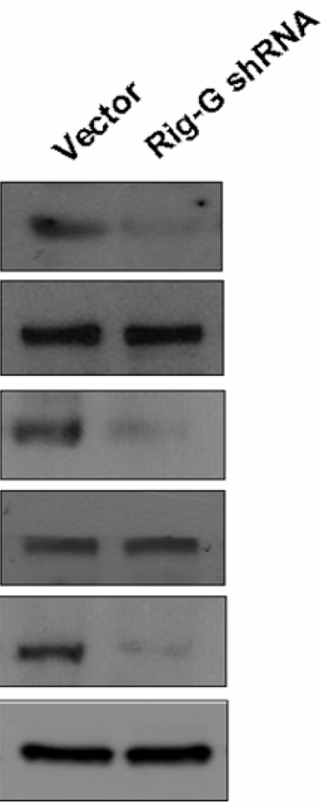

B

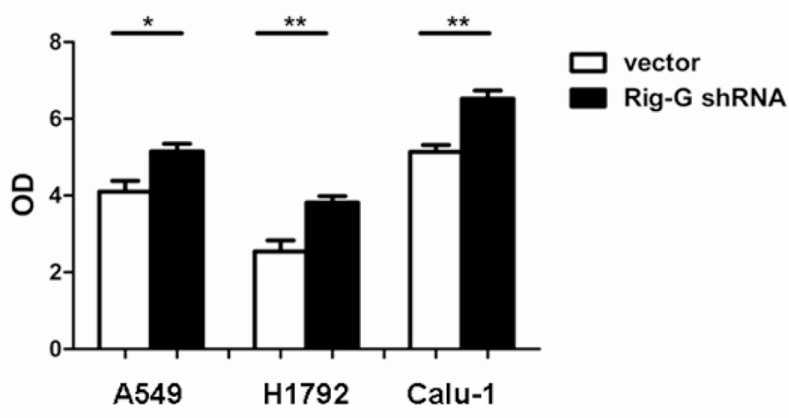

Rig-G inhibits a proliferation program and NF$\kappa \mathrm{B}$ activation in cancer cells

Because of the strong effect of Rig-G in inhibiting growth and colony formation in the ATRA-resistant cell line A549 cell, subsequent experiments were performed using the A549 cells. To characterize differentially expressed mRNA during tumor growth inhibition, we measured the mRNA profile of A549 cells with and without Rig-G overexpression. A549 cells without Rig-G overexpression (pTRE+DOX) were used as control, and A549 cells with Rig-G overexpression (Tet-On Rig$\mathrm{G}+\mathrm{DOX}$ ) were used as the experimental group. Microarray analysis showed that Rig-G overexpression results in the downregulation of the Kyoto Encyclopedia of Genes and Genomes (KEGG) cancer, cell cycle, NF-кB pathways

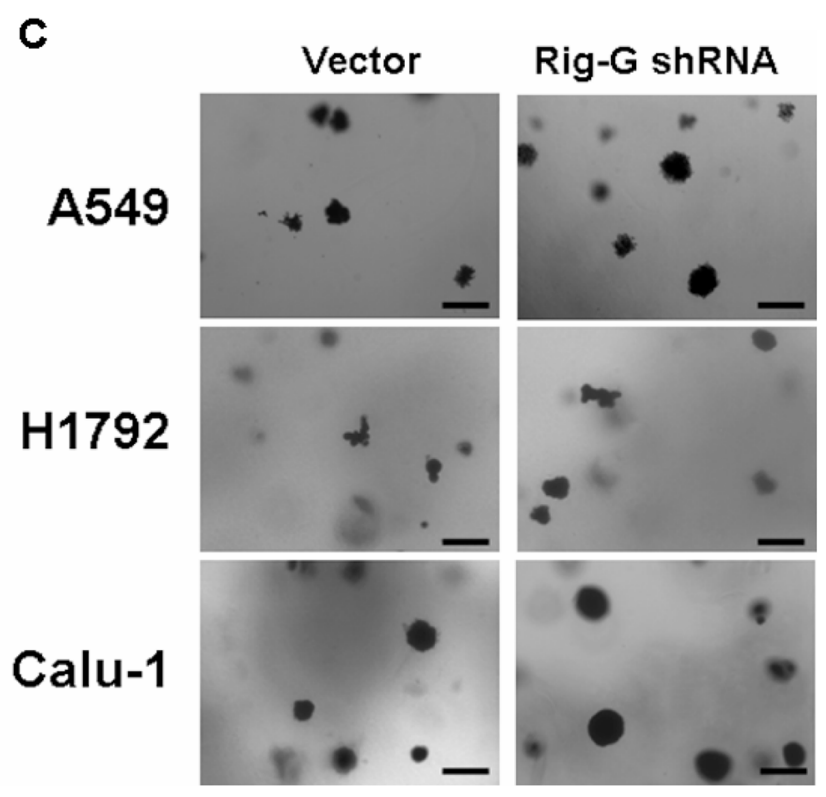

D

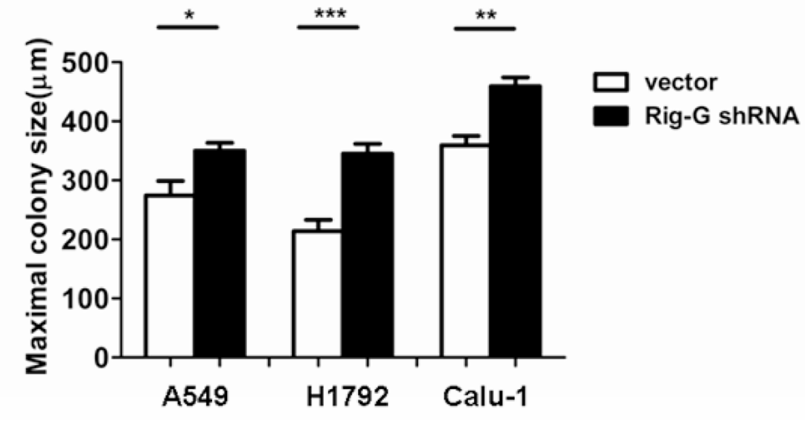

Figure 3: Rig-G knockdown increases lung cancer cell growth. A. Lung cancer cell A549, H1792, and Calu-1 were transduced with indicated shRNA. After selection, expression of Rig-G proteins was analysed. B. The indicated cells were transduced with control or Rig-G shRNA plasmids, and their proliferation was measured by ELISA (BrdU labeling) analysis. The results are expressed as the mean \pm SEM, ${ }^{*} p<0.05 ; * *<0.01$. C. The growth of tumor cells transduced with indicated shRNA plasmids in soft agar was assessed by using an anchorage-independent colony formation assay. Scale bars $=500 \mu \mathrm{m}$. D. The maximum colony size assay in A549, H1792, and Calu-1 cells transfected with the indicated shRNA plasmids. The results are expressed as the mean $\pm \mathrm{SEM}, * p<0.05 ; * * p<0.01 ; * * * p<0.001$. 
[Gene Set Enrichment Analysis (GSEA): $\mathrm{P}=0.017,0.001$, and 0.001$]$ and other pathways and categories related to tumorigenesis (Table 1). Notably, KEGG chemokine and cytokine-cytokine receptor interactions, which are responsible for generating an inflammatory response, were also downregulated by Rig-G overexpression. Next, we generated a heat map that shows a differentially gene expression profile pattern between with and without Rig-G overexpression in A549 cells (Figure 5A).

We then investigated whether specific growth pathways and inflammatory response are inhibited by Rig-G. In contrast to the A549 cells without Rig-G overexpression, expression of cyclin D1, c-myc, and PCNA was inhibited in response to Rig-G overexpression in A549 cells (Figure 5B). We also observed that the expression of cell cycle inhibitors p21 and p27 was high in A549 cells with Rig-G overexpression and low in A549 cells without Rig-G overexpression (Figure 5B). These results were in correlation with those obtained by measuring xenograft tumor size or Ki-67 immunostaining. Furthermore, inflammationrelated genes were examined by real-time PCR, which showed that the expression of Il6, Tnf $\alpha$, and Il1 $\beta$ were strongly inhibited in Rig-G overexpressing cells (Figure 5C). These findings indicate that Rig-G mediates the induction of inflammatory mediators, thereby suggesting that the cell growth suppressive actions of Rig-G are also likely to be correlated with the modulation of inflammatory genes.

$\mathrm{NF}-\kappa \mathrm{B}$ has a key role in the oncogenesis, apoptosis, immune, and inflammatory responses that modulate transcription of various genes that encode growth factors, anti-apoptotic proteins, cytokines, and cell adhesion molecules [19]. We examined whether Rig-G inhibited

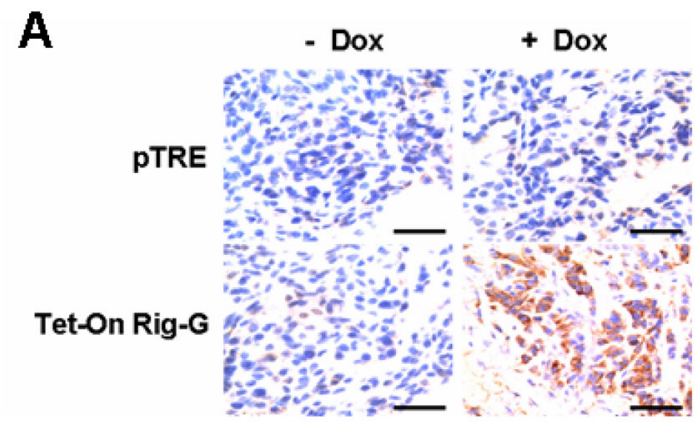

B

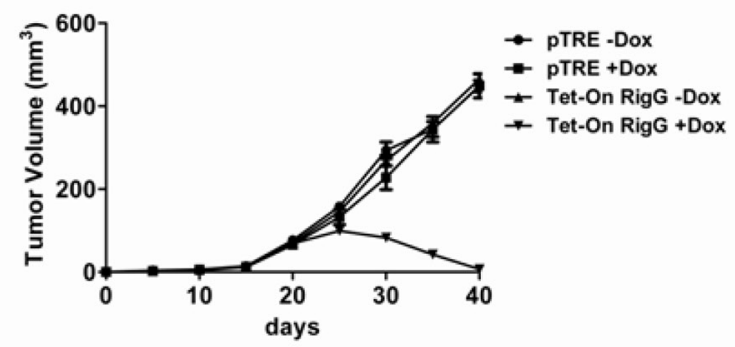

C

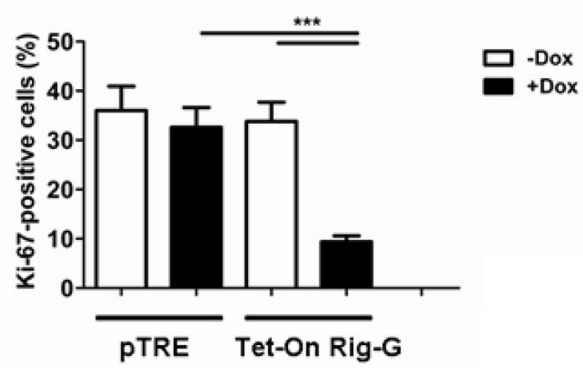

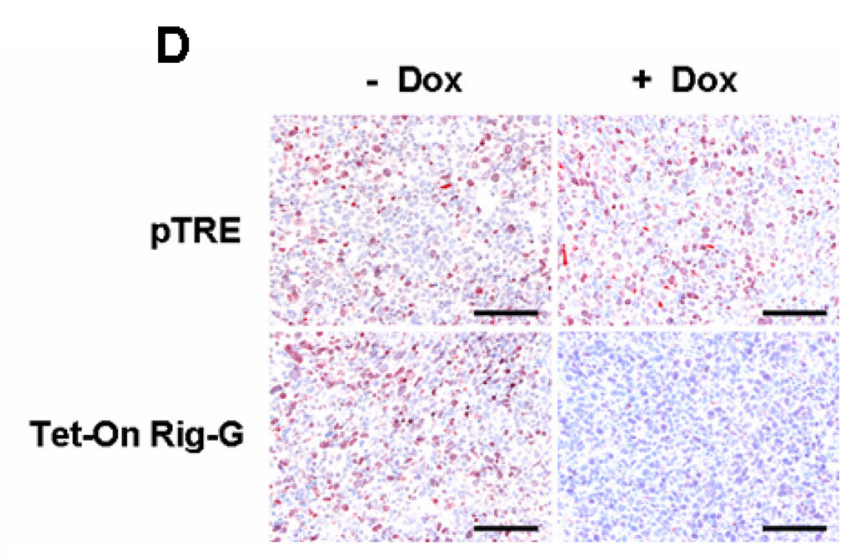

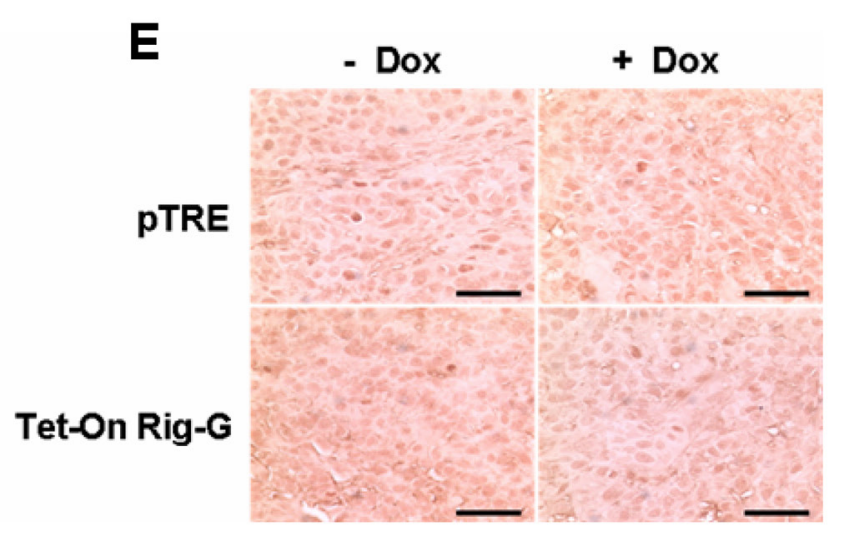

Figure 4: Rig-G protein results in decreased tumor growth in vivo. A. Nude mice were injected subcutaneously with the indicated cell lines, and the expression of Rig-G was examined by immunohistochemistry of paraffin-embedded sections. Scale bars $=$ $100 \mu \mathrm{m}$. B. Tumors overexpressing Rig-G showed significantly slower growth $(\mathrm{n}=5)$. C. Percentage of Ki-67-positive tumor cells. The results are expressed as the mean \pm SEM, $(n=5), * * * p<0.001$. D. Paraffin-embedded tumor sections were analyzed after staining with an anti-Ki-67 antibody. Scale bars $=100 \mu \mathrm{m}$. E. Apoptotic cells were identified by TUNEL staining. Scale bars $=100 \mu \mathrm{m}$. 
Table 1: 20 downregulated pathways found by a GSEA between A549 cell with and without Rig-G overexpression

\begin{tabular}{lcc}
\hline KEGG Pathway & P value & Enrichment \\
\hline Pathways in cancer & 0.017 & Down \\
Wnt signaling pathway & 0.006 & Down \\
NF-kB signaling pathway & 0.001 & Down \\
Axon guidance & 0.023 & Down \\
Renal cell carcinoma & 0 & Down \\
Cell cycle & 0.001 & Down \\
Chemokine signaling pathway & 0 & Down \\
Cytokine-cytokine receptor interaction & 0 & Down \\
Arginine and proline metabolism & 0.007 & Down \\
Retinol metabolism & 0.002 & Down \\
Complement and coagulation cascades & 0.003 & Down \\
VEGF signaling pathway & 0.002 & Down \\
Terpenoid backbone biosynthesis & 0 & Down \\
Glycerophospholipid metabolism & 0.031 & Down \\
Aminoacyl-tRNA biosynthesis & 0.018 & Down \\
Tryptophan metabolism & 0.001 & Down \\
Cell adhesion molecules (CAMs) & 0.0004 & Down \\
DNA replication & 0.002 & Down \\
Endocytosis & 0.004 & Down \\
Nucleotide excision repair & 0 & Down \\
\hline
\end{tabular}

The enrichment is relative to the enrichment specifier and relative to the A549 without Rig-G overexpression.

growth and the inflammatory response of A549 cells through a NF- $\mathrm{kB}$ intermediate. Western blotting was performed on cell nuclear proteins to assess the levels of p65 in A549 cells with and without Rig-G overexpression. The level of p65 in nuclear proteins was significantly lower in Rig-G overexpression cells compared with the cells without Rig-G overexpression (Figure 6A). By immunofluorescence staining, we noted that when Rig-G overexpression in A549 cells, the nuclear p65 was markedly diminished. A colocalization of $\mathrm{p} 65$ and Rig-G in the cytoplasm was shown by superimposition of the staining for these two proteins, indicating that decreased p65 level in nuclear of A549 with Rig-G overexpression is due to the interference of Rig-G (Figure 6B). Furthermore, NF- $\kappa B$ activation was measured with a Trans $A M \AA$ ELISA kits, and found that Rig-G resulted in a significant inhibition of NF- $\mathrm{kB}$ activation in A549 cells ( $24 \mathrm{~h}$ after Dox treatment) (Figure 6C). This result was confirmed by EMSA determination. Cell nuclear proteins were used to test for their binding to NF- $\mathrm{kB}$ probe. By EMSA, we observed a decrease in NF- $\kappa$ B DNA binding activity in A549 cells with Rig-G overexpression (Figure 6D).
These results indicated that Rig-G is an important NF- $\mathrm{kB}$ inhibitor in NSCLC cells.

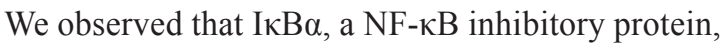
was strongly upregulated in Rig-G overexpression cells (Figure 7A). IкB $\alpha$ ubiquitination and proteasomal degradation were determined to be required for the activation of NF-KB. To investigate whether Rig-G impacts I $\mathrm{KB} \alpha$ ubiquitination, we performed an immunoprecipitation assay using Tet-On A549 cells. Rig- $G$ significantly impaired the ubiquitination of $I \kappa B \alpha$ in Rig-G overexpression cells (Figure 7B). TNF $\alpha$ has been previously reported to trigger NF- $\mathrm{KB}$ activation [20]. The present study showed that although treatment of cells with TNF $\alpha$ increased the activation of NF$\kappa \mathrm{B}$, as expected, Rig-G blocked the $\mathrm{TNF} \alpha$-mediated activation of NF- $\kappa B$ (Figure $7 \mathrm{C}$ ). The NF- $\mathrm{kB}$-driven luciferase reporter gene assay showed that $\mathrm{TNF} \alpha$-induced binding of NF- $\mathrm{KB}$ to its DNA consensus sequence was significantly decreased in Rig-G overexpressing cells, as displayed by a decrease in luciferase activation, thereby demonstrating the inhibitory effect of Rig-G on TNF $\alpha$ mediated activation of NF- $\mathrm{KB}$ (Figure 7D). Furthermore, 
the cells overexpressing Rig-G revealed marked inhibition of TNF $\alpha$-induced degradation of $\mathrm{I} \kappa \mathrm{B} \alpha$, as well as a significant decrease in ubiquitination (Figure 7E). To gain further insights into the role of NF- $\mathrm{B}$ in RIGG-induced cell growth inhibition, we generated stable A549 cell lines (pTRE and Tet-On Rig-G) containing short hairpin RNA (shRNAs) specific to p65 (Figure $8 \mathrm{~A})$. Cell proliferation was markedly reduced when NF$\kappa \mathrm{B}$ was inactivated in pTRE A549 cells (Figure $8 \mathrm{~B}$ ). NF- $\kappa$ B deficiency in pTRE A549 cells also decreased colony formation ability (Figure 8C, 8D). We observed a significant decrease in cell proliferation and colony formation in Tet-On Rig-G A549 cells with NF-кB deficiency in comparison with control (Tet-On Rig-G A549 cells) (Figure 8B, 8C, 8D). Collectively, these results indicated that the inhibition of $N F-\kappa B$ activation is likely the major cell proliferation-inhibiting mechanism of Rig-G in NSCLC cells.

\section{Rig-G inhibits NF-אB activity and is mediated by} STAT3

To gain further insights into the molecular mechanism by which Rig-G inhibits NF- $\mathrm{B}$ activity, the expression of STAT3 and STAT3-related genes was analyzed before and after Rig-G induction. In agreement with the reduction in IL- 6 production, we observed that the levels of STAT3 mRNA and protein were inhibited in Rig-G overexpressing A549 cells, but not in control cells (Figure 9A, 9B). STAT3 phosphorylation on Tyr705 was also significantly decreased in A549 cells with Rig-G overexpression (Figure 9B). Moreover, the expression of STAT3 targeting gene products, $\mathrm{Bcl} 2$ and VEGF, in A549 cells was also reduced by Rig-G (Figure 9B). The above experiments of STAT3 inactivation were repeated using the other ATRA-sensitive lung cancer cell lines, H1792, and Calu-1. Results were very

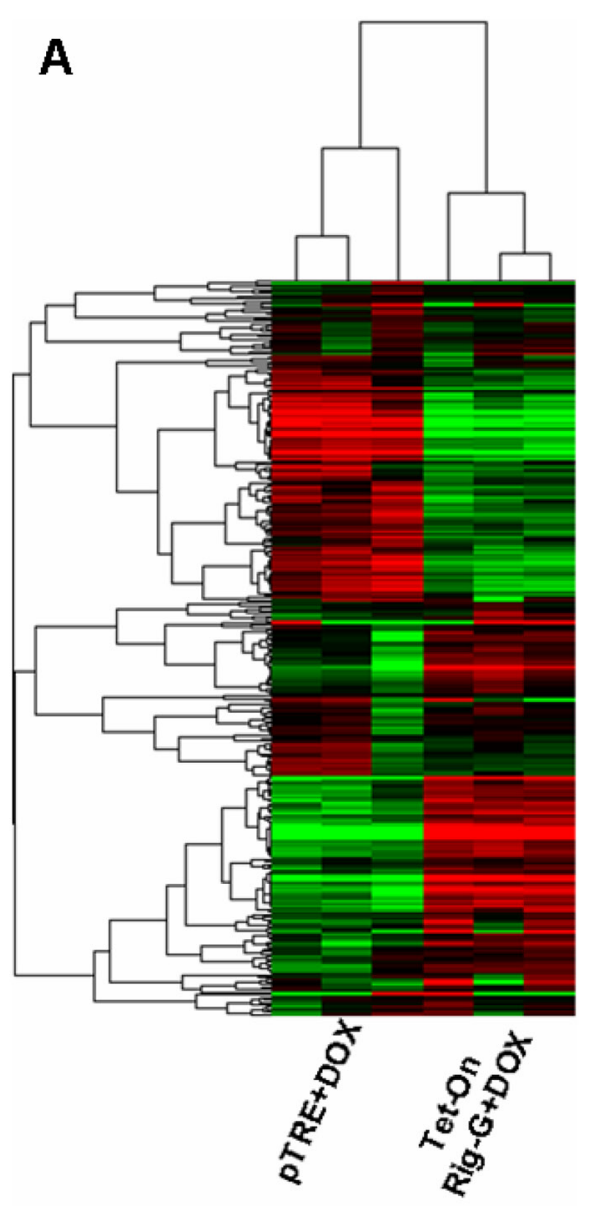

$\mathbf{B}$
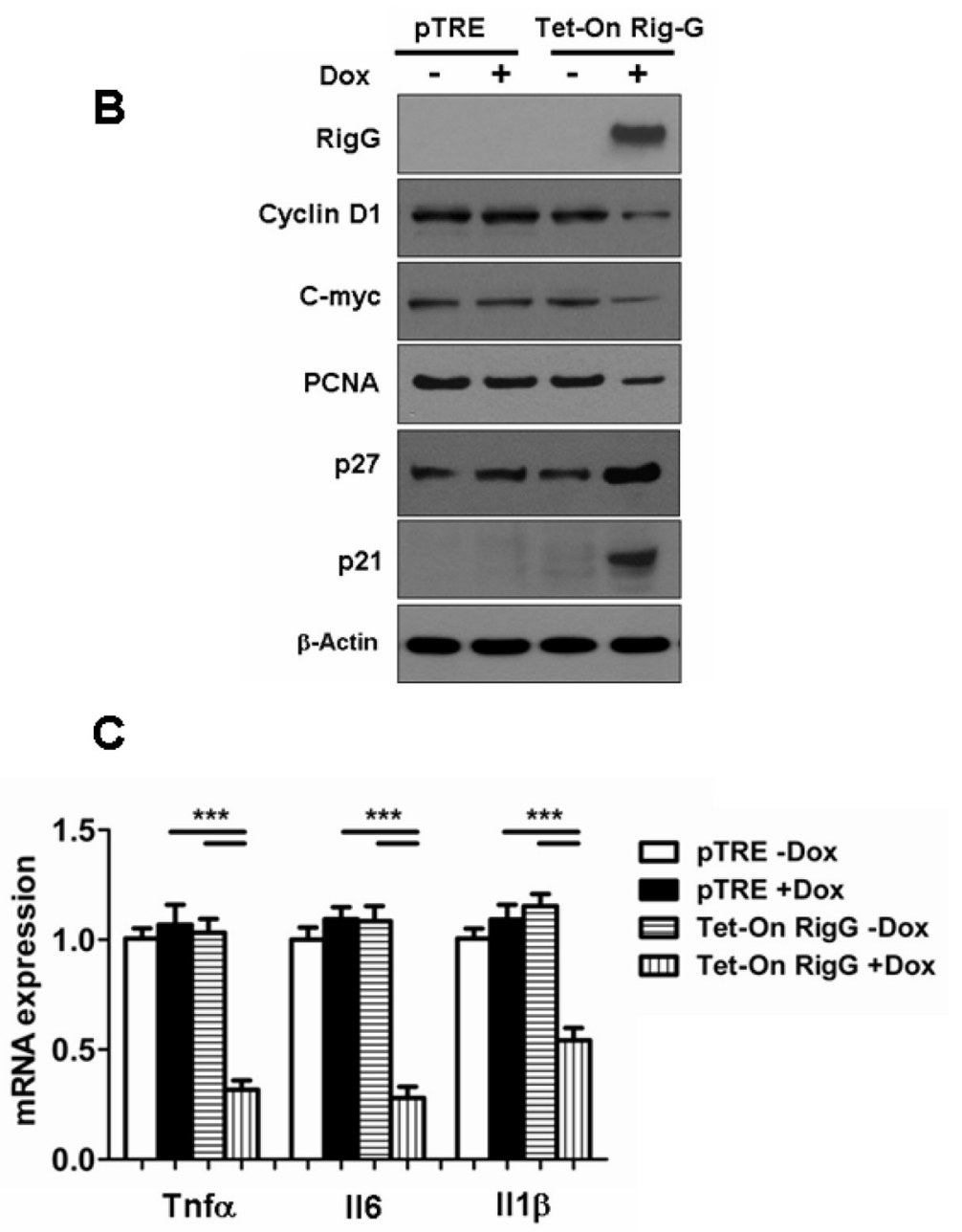

Figure 5: Rig-G inhibits specific growth pathways and inflammatory responses in tumor cells. A. Heat map of the experimental groups. Dendrogram and cluster analyses show a differential gene expression profile pattern in A549 cell lines with (right) and without (left) Rig-G overexpression. Green indicates downregulation, and red indicates upregulation. B. The expression of proliferationrelated proteins in the indicated cells was analyzed by western blotting. C. Induction of inflammatory cytokine mRNAs in the indicated cells was measured by real-time PCR. The results are expressed as the mean $\pm \operatorname{SEM}(\mathrm{n}=5), * * * p<0.001$. 
similar to those obtained in A549 cell line with RIG-G overexpression. The expression of RIG-G resulted in considerable reduction in phosphorylated STAT3 in both cell lines (Figure 9C and 9D).

To confirm the effect of STAT3 restoration on NF$\kappa \mathrm{B}$ activity, we stably transfected Tet-On A549 cells with a STAT3-expression construct or an empty vector as control. As expected, STAT3 transfection restored NF$\kappa \mathrm{B}$ activity (Figure 10A), as well as antagonized RigG-induced inhibition of colony formation (Figure 10B, 10C) and growth (Figure 10D) in Tet-On A549 cells compared to that in control cells, which showed no Rig-G overexpression. Next, we generated stable A549 cell lines containing short hairpin RNA (shRNAs) specific to STAT3. Silencing of STAT3 significantly reduced NF- $\kappa$ B activity in pTRE A549 cells (Figure 10E). Furthermore, in A549 cells with Rig-G overexpression, silencing of STAT3 further reduced the activation of $\mathrm{NF}-\kappa \mathrm{B}$ (Figure 10E). We also examined the proliferation and colony formation ability of A549 cell with STAT3-knocked down. We found that silencing of STAT3 also reduced the proliferation and colony formation ability of A549 cell without Rig-G overexpression (Figure 10F, 10G, 10H). Silencing of STAT3 further inhibited colony formation and growth of A549 cell with Rig-G overexpression (Figure 10F, 10G, $10 \mathrm{H})$. These findings suggested that STAT3 might be the main mediator through which Rig-G inhibits NF- $\kappa$ B in cancer cells.

Previous studies have shown that STAT3 activation directly induces NF- $\kappa$ B-activated miR21 and miR181b-1 expression [17]. We propose that STAT3 and its downstream effectors are responsible for Rig-G-induced inhibition of NF- $\kappa$ B. As expected, we observed a dramatic decrease in the levels of miR21 and miR181b-1 expression in RigG-expressing A549 cells (Figure 11A), and the individual expression of miR21 or miR181b-1 significantly reduced
A

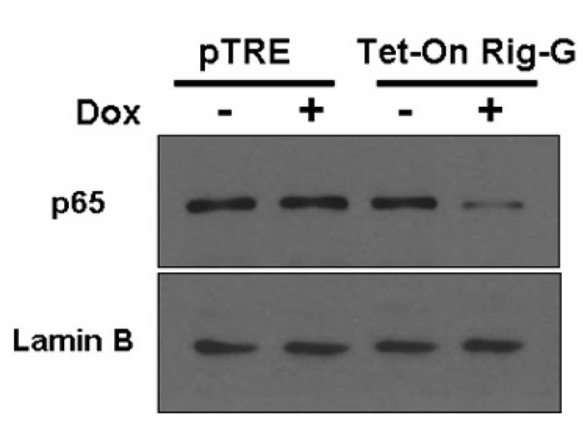

C

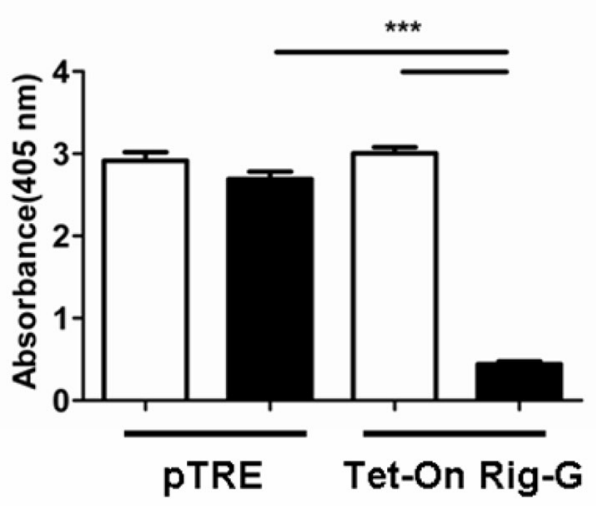

B
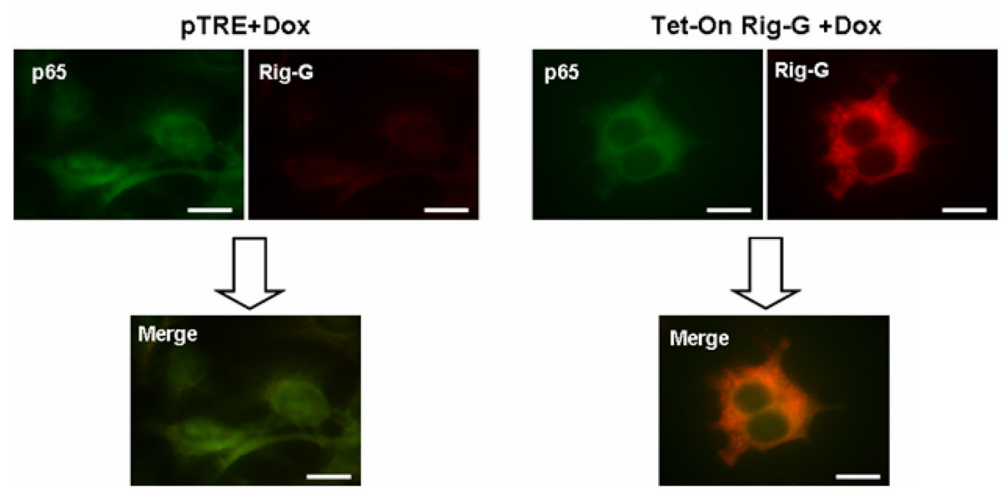

D

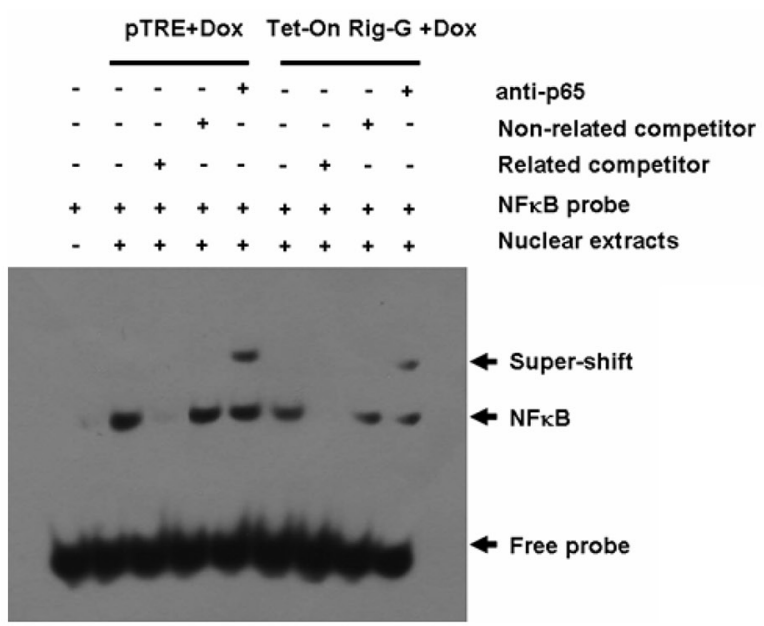

Figure 6: Rig-G inhibits NF-кB activation in A549 cells. A. The A549 sublines pTRE and Tet-On Rig-G were cultured, respectively, in the absence or presence of Dox $(2 \mu \mathrm{g} / \mathrm{mL})$ for $24 \mathrm{~h}$. Nuclear protein from A549 cells was isolated. The expression of the indicated protein was analyzed by Western blot. B. Double-color immunofluorescence analysis was performed with the combination of anti- Rig-G (red) and anti-p65 (green). Scale bars $=10 \mu \mathrm{m}$. C. NF- $\kappa$ B activation was measured by ActivELISA assay in A549 cells with and without Rig-G overexpression. The results are expressed as the mean $\pm \operatorname{SEM}(\mathrm{n}=3), * * * p<0.001$. D. EMSA analysis of the DNA binding of NF- $\kappa B$. 
the inhibition of NF- $\kappa$ B activity by Rig-G (Figure 11B), indicating that the downregulation of these microRNAs is important for Rig-G-mediated inhibition of NF- $\kappa$ B activation.

In accordance to a previous study that determined that the PTEN/Akt pathway that regulates NF- $\kappa$ B activity was controlled by miR21 in tumor cells, we examined PTEN expression and Akt phosphorylation in A549 cells before and after Rig-G induction. We observed that PTEN expression in cultured A549 cells was upregulated by Rig-G (Figure 11C). Akt phosphorylation of Ser473 was decreased in the total protein prepared from Rig-G overexpressing A549 cells (Figure 11C). Furthermore, treatment of cells with the PTEN inhibitor, bpV(phen) $(10 \mu \mathrm{M})$, blocked the Rig-G-mediated inhibition of NF$\kappa \mathrm{B}$ activation (Figure 11D). These findings suggest that Rig-G inhibits NF- $\kappa \mathrm{B}$ activity by regulating the PTEN/ Akt pathway.

We have shown previously that Rig-G prevents the ubiquitination of $\mathrm{I} \kappa \mathrm{B} \alpha$, and CYLD, a deubiquitinating enzyme, is a direct target of miR181b-1 [17]. To address whether the observed inhibition of ubiquitination in I $\mathrm{B} \alpha$ is relevant to the expression of CYLD, we examined the expression of this enzyme. A significant upregulation of the CYLD was observed in the A549 cells with Rig-G overexpression both at the level of protein and mRNA (Figure 11C, 11E). Silencing of CYLD in A549 cells via siRNA significantly increased NF- $\kappa$ B activation of Rig-G overexpressing A549 cells compared to cells without Rig-G overexpression (Figure 11F). Thus, the miR181b-1/ CYLD pathway is also involved in the inhibition of NF$\kappa \mathrm{B}$ activation subsequent to Rig-G expression.

To further confirm the role of STAT3, we analyzed the expression of STAT3 targeting genes, miR21, miR181b-1, CYLD and PTEN, in Rig-G regulated STAT3 expression or knocked down A549 cells. In Rig-G overexpressing A549 cells, Rig-G expression resulted in a reduction in the induction of miR21 and miR181b-1 and an increase in the expression of CYLD and PTEN, which is blocked by the ectopic expression of STAT3 (Figure 12A, 12C). Silencing of STAT3 in pTRE A549 cells significantly reduced the expression of miR21 (Figure 12B). In Rig-G overexpressing A549 cells, knockdown of STAT3 exhibited a lower miR21 level than control (Figure 12B). Similar results were seen in the expression
A

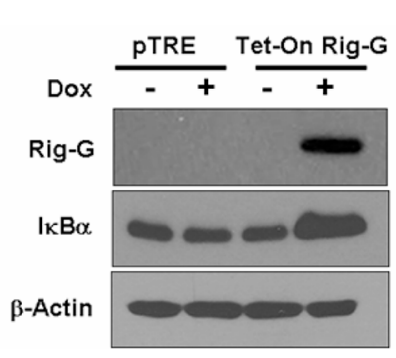

B

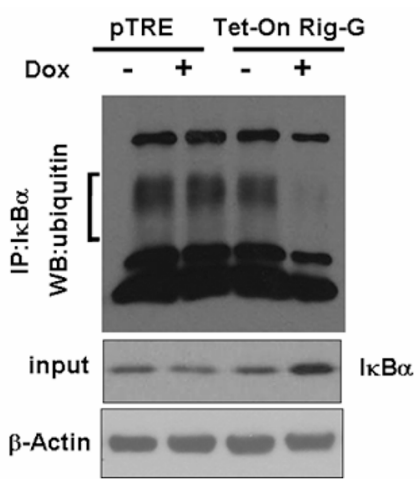

C

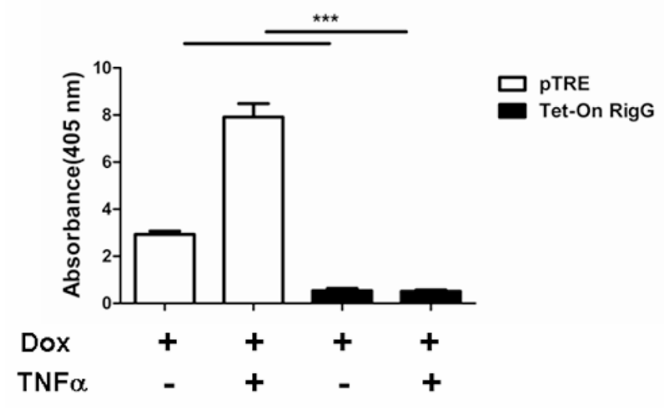

E
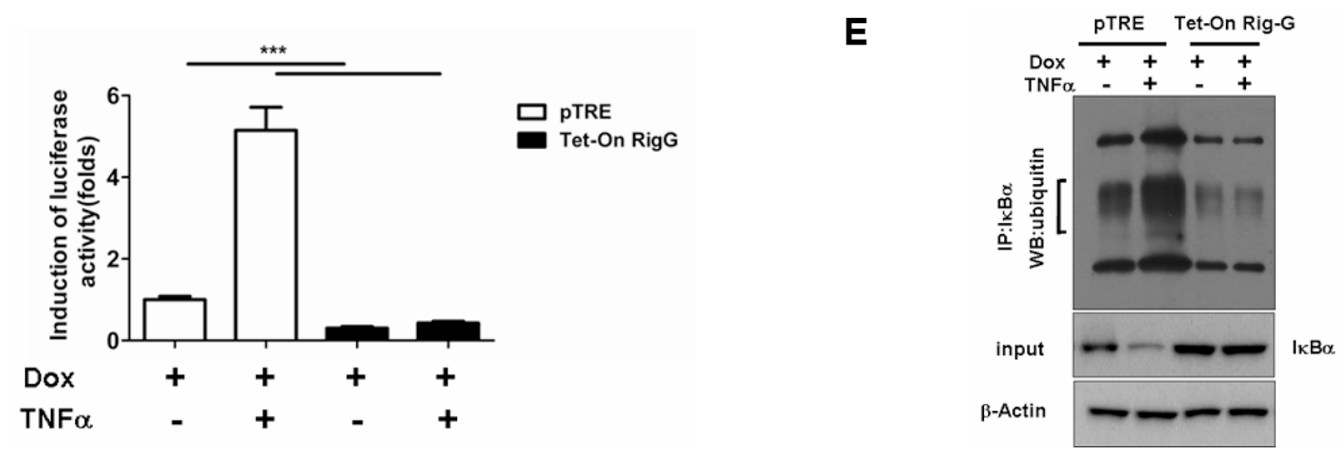

Figure 7: Effects of Rig-G protein on IкB $\boldsymbol{\alpha}$ degradation. A. Western blotting analysis of IкB $\alpha$ expression in A549 sublines pTRE and Tet-On Rig-G. The cells were cultured respectively in the presence or absence of Dox $(2 \mu \mathrm{g} / \mathrm{mL})$ for $24 \mathrm{~h}$. B. The pTRE and Tet-On Rig-G cells were incubated with the proteasome inhibitor MG132 $(20 \mu \mathrm{M})$ for $5 \mathrm{~h}$, lysed, and subjected to immunoprecipitation (IP) with anti- I $\mathrm{B} \alpha$ antibody. The resulting precipitates were detected by Western blot analysis with antiubiquitin antibodies. C. NF- $\kappa \mathrm{B}$ activation in the indicated cells untreated or treated with $1 \mathrm{ng} / \mathrm{mL} \mathrm{TNF} \alpha$ for $1 \mathrm{~h}$. The results are expressed as the mean $\pm \operatorname{SEM}(\mathrm{n}=3), * * * p<0.001$. D. The effect of Rig-G on the TNF-mediated inducibility of an NF- $\kappa$ B reporter construct. E. The indicated cells were incubated with the proteasome inhibitor MG132 $(20 \mu \mathrm{M})$ for $5 \mathrm{~h}$, and cells were untreated or treated with $1 \mathrm{ng} / \mathrm{mL} \mathrm{TNF} \alpha$ for $1 \mathrm{~h}$, and cell lysates were immunoprecipitated (IP) with an anti-IкB $\alpha$ antibody, followed by Western blot analysis with an anti-ubiquitin antibody. 
of miR181b-1 (Figure 12B). Expression of CYLD and PTEN were induced in response to STAT3 knockdown or Rig-G overexpression, and both proteins has a modest increase in STAT3 knockdown A549 cells with Rig-G overexpression (Figure 12D). These results are consistent with those obtained by measuring miR21 and miR181b-1.

Taken together, these results are consistent with a pathway in which Rig-G inhibits STAT3, leading to decreased miR21 and miR181b-1 expression and subsequent regulation of PTEN/Akt and CYLD/I $\kappa \mathrm{B} \alpha$ pathways, which inhibit the activity of NF- $\mathrm{KB}$.

\section{DISCUSSION}

The main finding of the present study is that Rig-G is a growth inhibition factor of lung cancer cells. The protein inhibits NF- $\kappa$ B activity by suppressing STAT3 in lung cancer cells. The decreased expression of miR21 and miR181b-1 and subsequent modulation of PTEN/Akt and

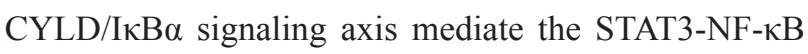
pathway via Rig-G.

It has been previously reported that the induction of Rig-G by ATRA occurs in various types of cancers, not merely in acute promyelocytic leukemia but also in head and neck squamous carcinoma cells and ovarian cancer, suggesting that Rig-G may have similar effects in different cell contexts $[8,18]$. In the present study, we examined the expression of Rig-G in lung cancer cell lines. We found that lung cancer cell lines such as A549, H1792, and Calu-1 exhibited ATRA-induced expression of Rig-G. The baseline expression of Rig-G varied in different lung cancer cell lines, although a rapid induction was observed at $24 \mathrm{~h}$ after ATRA treatment, which exhibited ATRA sensitivity that was comparable to some lung cancer cells such as Calu-1 and H1792. The expression regulation of Rig-G may have resulted from different mechanisms: (1) Our previous studies showed that ATRA induces Rig-G expression by activation of the JAK-STAT1
A

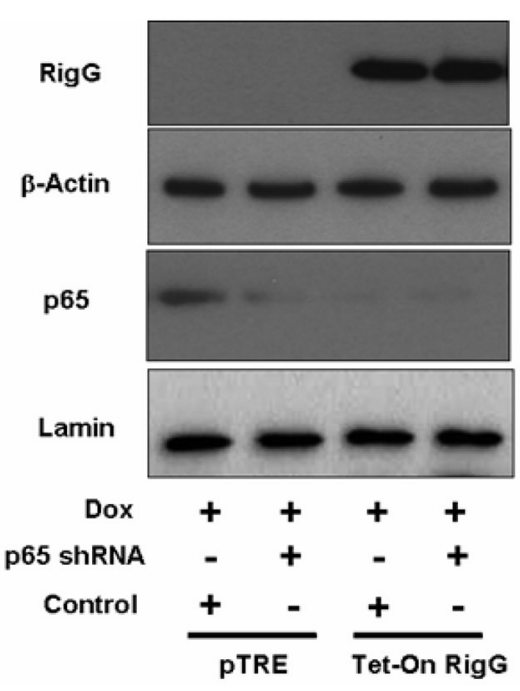

B

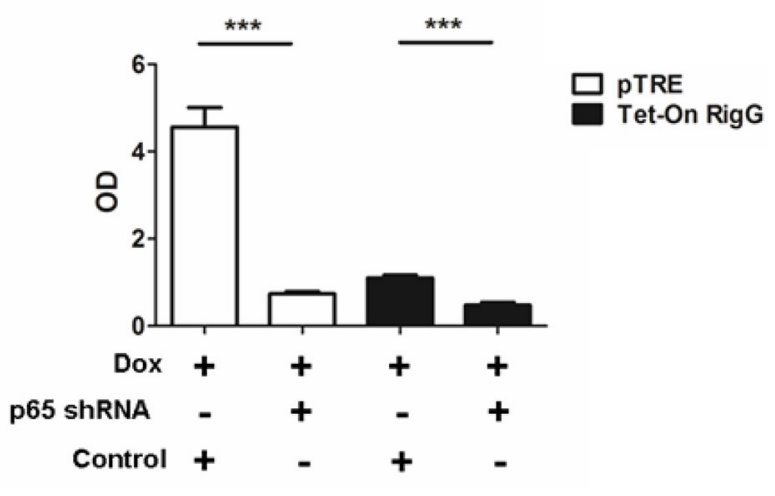

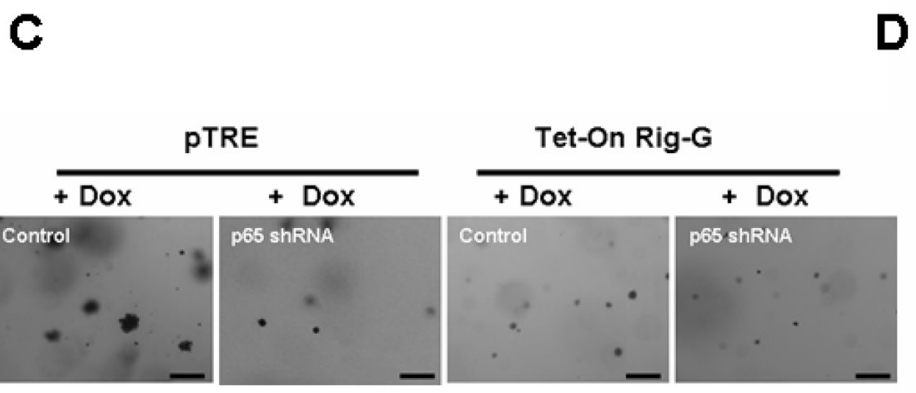

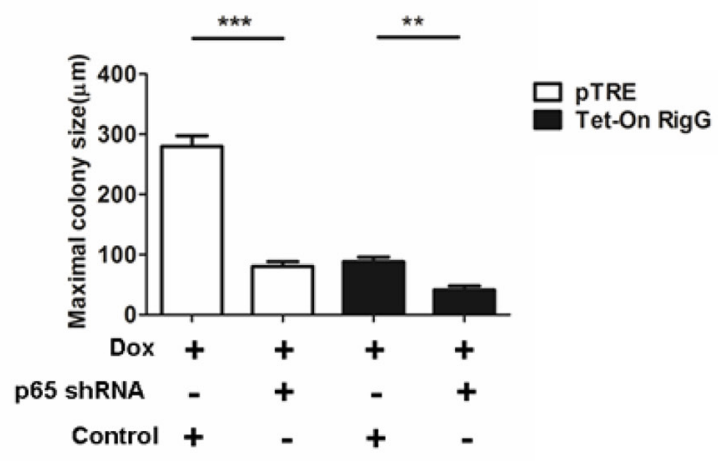

Figure 8: NF-кB is important in RIG-G-induced cell growth inhibition. A. A549 sublines pTRE and Tet-On Rig-G were transduced with indicated shRNA plasmids. After selection, the cells were cultured, respectively, in the absence or presence of Dox $(2 \mu \mathrm{g} / \mathrm{mL})$ for $24 \mathrm{~h}$, expression of the indicated proteins was analysed. B. The indicated cells were transduced with control or p65 shRNA plasmids, and their proliferation was measured by ELISA (BrdU labeling) analysis. The results are expressed as the mean \pm SEM, $* * * p$ $<0.001$. C. The growth of tumor cells transduced with indicated shRNA plasmids in soft agar was assessed by using an anchorageindependent colony formation assay. Scale bars $=500 \mu \mathrm{m}$. D. The maximum colony size assay in A549 sublines pTRE and Tet-On Rig-G cells transfected with the indicated shRNA plasmids. The results are expressed as the mean $\pm \mathrm{SEM},{ }^{* *} p<0.01 ; * * * p<0.001$. 
pathway, which is involved in the expression of IRF-1/ IFN- $\alpha$ [8]. (2) IRF-9/STAT2 functional interaction drives the expression of Rig-G independent of STAT1 and the classical JAK-STAT pathway [21]. IRF-1 also induces Rig-G expression via an IRF-9/STAT2-dependent or IRF9/STAT2-independent mechanism [21]. (3) STAT1 could significantly enhance the effects of the IRF-9/STAT2 complex or IRF-1 on Rig-G induction via an activated JAK-STAT pathway [22]. (4) The expression of PU.1 by ATRA directly binds to the promoter and increases the expression of Rig-G [23].

Although Rig-G is known as an anti-proliferative factor, it has only been proven to be critical for growth inhibition in a leukemia model [8]. Here, we demonstrate that specific Rig-G overexpression in lung cancer cells interferes with tumor cell proliferation and tumor growth in xenograft models. Based on the expression of Rig-G in ATRA-sensitive cells (Calu-1 and H1792) or ATRA-resistant cells (A549), a correlation between the ability of ATRA to inhibit lung cancer cell growth and
ATRA-induced expression level of Rig-G was detected. Moreover, the relatively high level of Rig-G baseline expression and higher level of ATRA-induced Rig-G expression are highly likely an important mechanisms underlying the growth inhibitory effects of ATRA. Based on these results, we performed growth inhibitory experiments using a Rig-G overexpression cell model. Our results showed that Rig-G overexpression suppresses the growth of lung cancer cell lines, including ATRA-resistant A549 cells, indicating that Rig-G expression is necessary but not sufficient for conferring ATRA sensitivity to cells. Thus, because of the strong effect of Rig-G in inhibiting growth and colony formation in the ATRA-resistant cell line A549 cell, we choose it to perform the subsequent experiments for demonstrating the tumor inhibiting effect of Rig-G in the lung cancer.

The development of lung cancer has been related to inflammation, cell proliferation, apoptosis, and various signaling pathways, including the NF- $\kappa \mathrm{B}$ signaling pathways $[24,25]$. NF- $\kappa \mathrm{B}$ controls the expression of
A

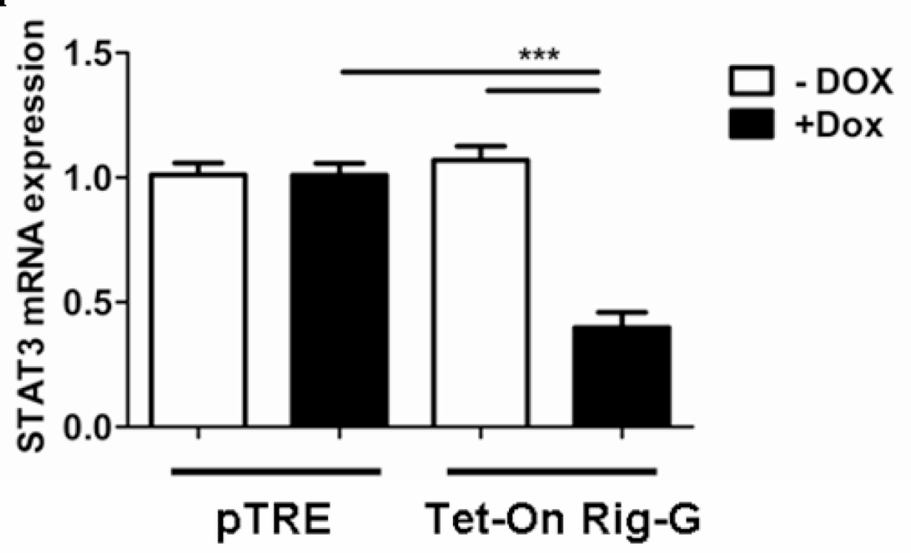

C

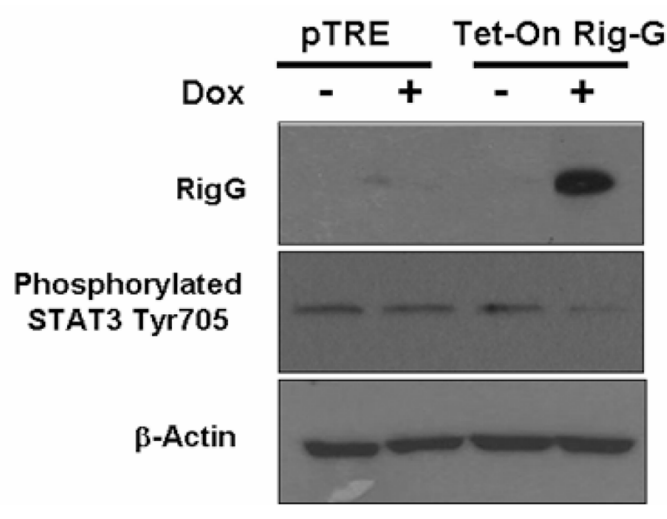

B

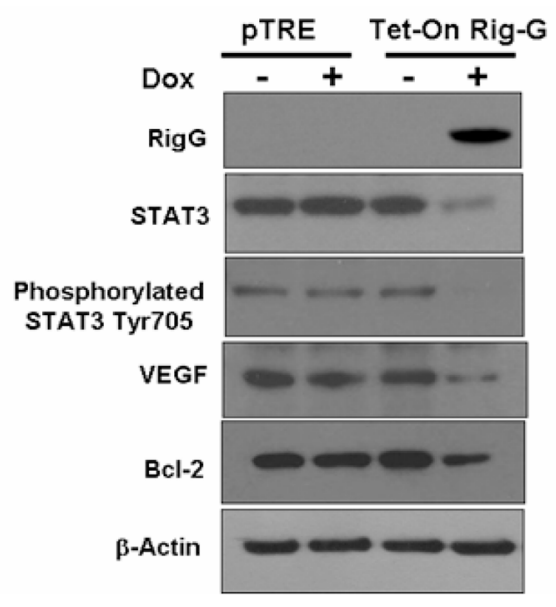

D

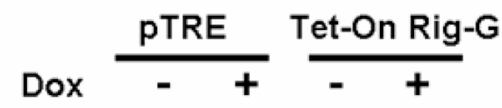

RigG

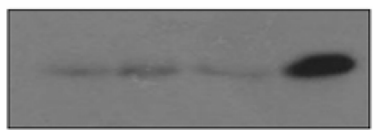

Phosphorylated STAT3 Tyr705

$\beta$-Actin

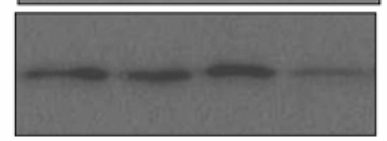

Figure 9: Rig-G inhibits STAT3 activity. A. Real-time PCR analysis of STAT3 mRNA expression in A549 sublines pTRE and TetOn Rig-G. The cells were respectively cultured in the presence or absence of Dox $(2 \mu \mathrm{g} / \mathrm{mL})$ for $24 \mathrm{~h}$. The results are expressed as the mean \pm SEM $(\mathrm{n}=5),{ }^{* * *} p<0.001$. B. A549 sublines pTRE and Tet-On Rig-G were analyzed for the expression of the indicated proteins by immunoblot analysis. C and D. H1792 (C), and Calu-1 (D) sublines pTRE and Tet-On Rig-G were analyzed for the expression of the indicated proteins by immunoblot analysis. 
A

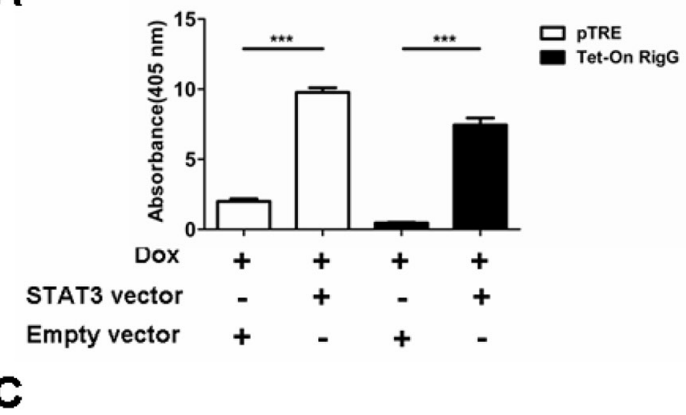

B

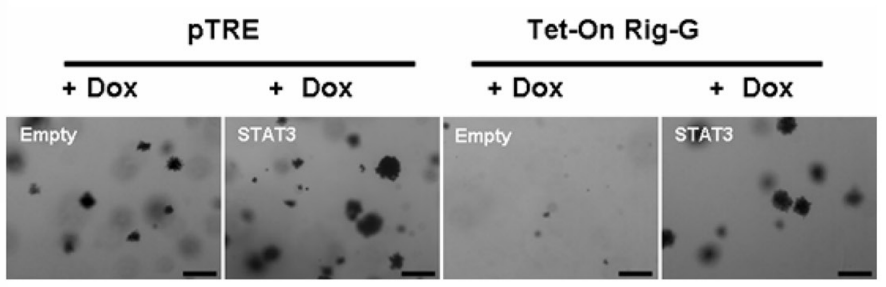

D
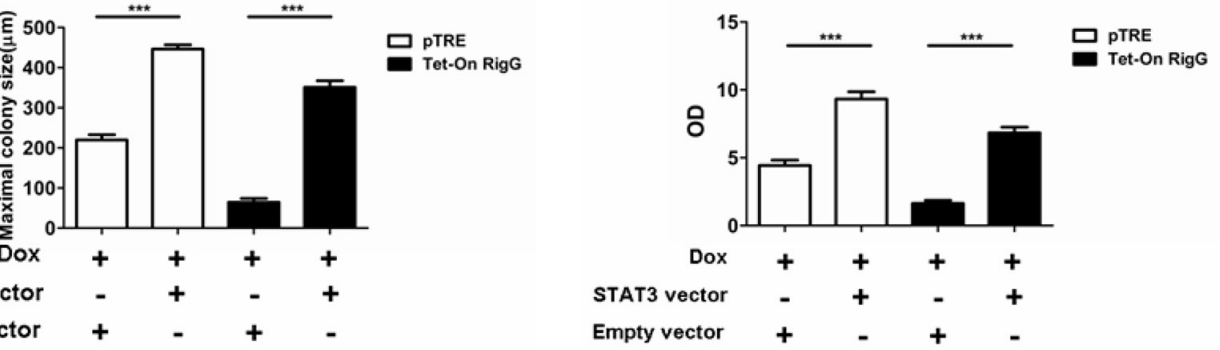

$\mathbf{E}$

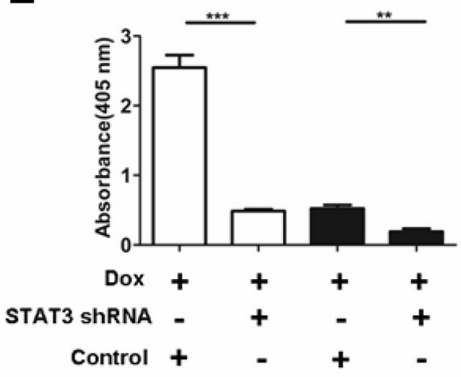

$\mathbf{F}$
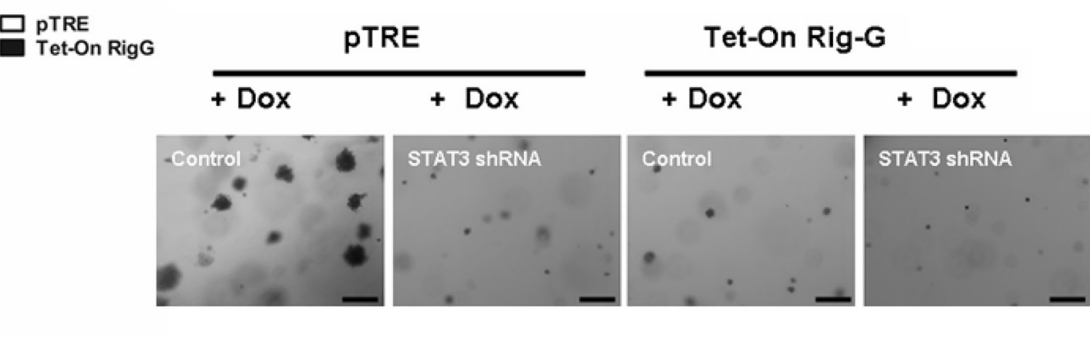

G

\section{H}
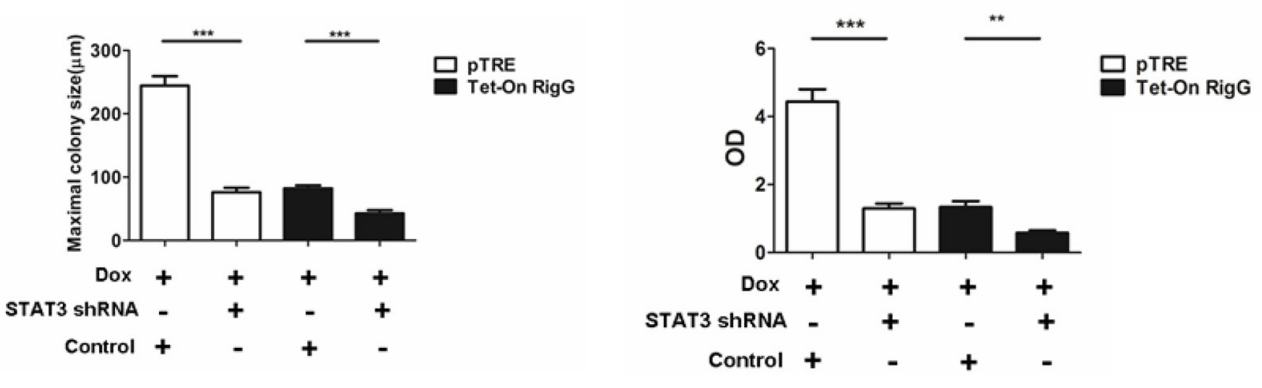

Figure 10: STAT3 inhibition is required for Rig-G decreasing lung cancer growth. A.The cells were cultured in the presence of Dox (2 $\mu \mathrm{g} / \mathrm{mL})$. NF-kB activity (ELISA assay) in A549 sublines pTRE and Tet-On Rig-G respectively transfected with an empty vector or STAT3 vector. The results are expressed as the mean \pm SEM $(n=3), * * * p<0.001$. B. Colony formation assay of A549 sublines pTRE and Tet-On Rig-G respectively transfected with empty vector or STAT3 vector. Scale bars $=500 \mu \mathrm{m}$. C. The maximum colony size of the indicated cells on soft agar was determined. The results are expressed as the mean $\pm \mathrm{SEM}, * * * p<0.001$. D. The proliferation of the indicated cells was measured by ELISA (BrdU labeling) analysis. The results are expressed as the mean \pm SEM, $* * * p<0.001$. E. A549 sublines pTRE and Tet-On Rig-G were transduced with indicated shRNA plasmids. After selection, the cells were cultured in the presence of Dox $(2 \mu \mathrm{g} / \mathrm{mL})$. NF-KB activity was assay by ELISA. The results are expressed as the mean \pm SEM $(\mathrm{n}=3),{ }^{* *} p<0.01$; ${ }^{* * *} p<0.001$. F. The growth of tumor cells transduced with indicated shRNA plasmids in soft agar was assessed by using an anchorageindependent colony formation assay. Scale bars $=500 \mu \mathrm{m}$. G. The maximum colony size assay in A549 sublines pTRE and Tet-On Rig-G cells transfected with the indicated shRNA plasmids. The results are expressed as the mean $\pm \mathrm{SEM}, * * * p<0.001$. H. The indicated cells were transduced with control or STAT3 shRNA plasmids, and their proliferation was measured by ELISA (BrdU labeling) analysis. The results are expressed as the mean $\pm \mathrm{SEM},{ }^{* *} p<0.01 ; * * p<0.001$. 
anti-apoptotic, pro-proliferative, and immune response genes, which is required in the pathogenesis of various cancers, including lung cancer, colon cancer, and hepatocellular carcinoma [26, 27]. Our previous studies have demonstrated that Rig-G upregulates the expression of cell cycle inhibitors p21 and p27 by downregulating c-myc or by preventing p27 from JAB-1-dependent and ubiquitin/proteasome-mediated degradation [8]. In the present study, the tumor-inhibiting activity of Rig-G is executed by antagonizing NF- $\kappa \mathrm{B}$ activation. NF- $\kappa \mathrm{B}$ in lung cancer cells is responsible for the induction of several anti-apoptotic and pro-proliferative proteins, as well as inflammatory factors, including Bcl-XL, Bcl-2, PCNA, and IL-6 [24, 28]. The inhibition of NF- $\mathrm{B}$ by Rig-G
A
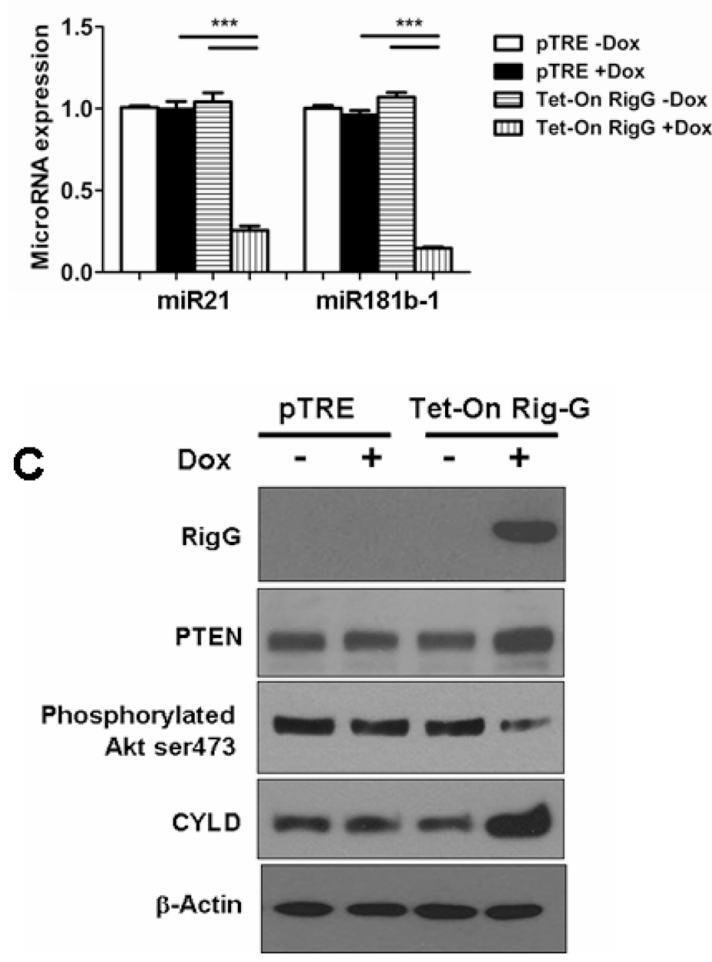

E

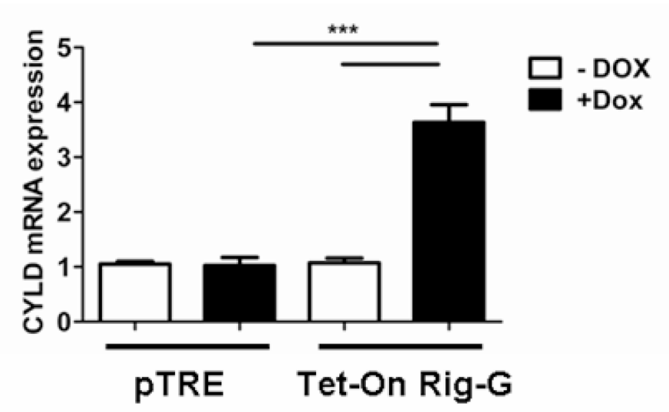

B
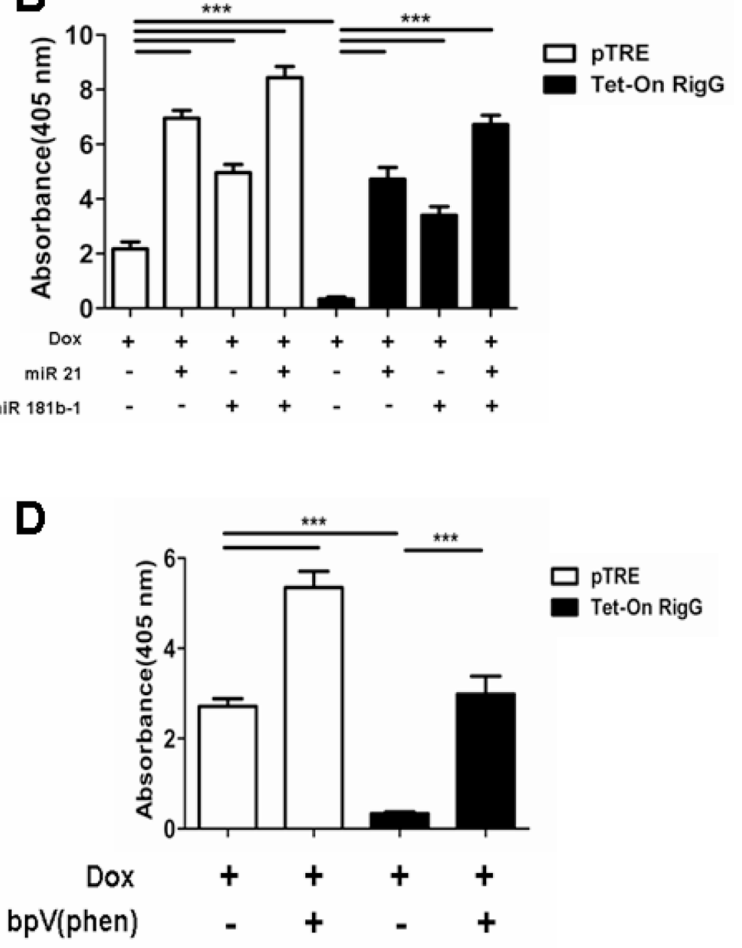

$\mathbf{F}$

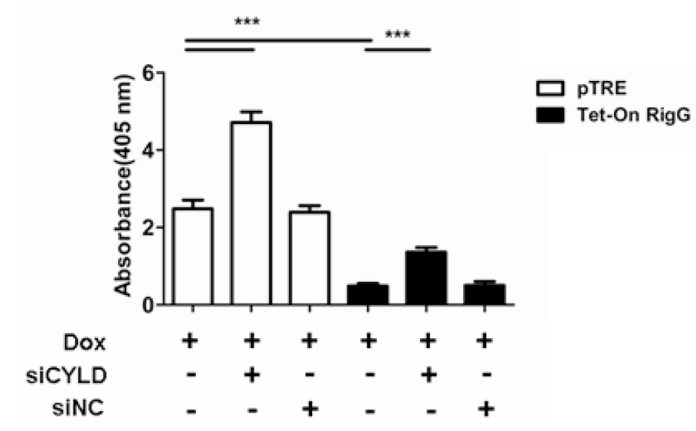

Figure 11: Rig-G inhibits NF- $\mathrm{B}$ activation through downregulation of MiR21/PTEN/Akt and miR181b-1/CYLD pathways. A. The cells were respectively cultured in the presence or absence of Dox $(2 \mu \mathrm{g} / \mathrm{mL})$ for 24 h. Real-time PCR analysis of MicroRNA expression levels in A549 cell lines with and without Rig-G overexpression. The results are expressed as the mean \pm SEM $(\mathrm{n}=5), * * * p<0.001$. B. NF-kB activation assay of A549 sublines pTRE and Tet-On Rig-G treated with miR-21 (100 nM), miR-181b-1 $(100 \mathrm{nM})$ for $24 \mathrm{~h}$. The results are expressed as the mean \pm SEM $(\mathrm{n}=3), * * * p<0.001$. C. A549 sublines pTRE and Tet-On Rig-G were analyzed for the expression of the indicated proteins by immunoblot analysis. D. NF-кB activation assay of A549 sublines pTRE and TetOn Rig-G treated with PTEN inhibitor bpV (phen) $(10 \mu \mathrm{M})$ for $24 \mathrm{~h}$. The results are expressed as the mean $\pm \operatorname{SEM}(\mathrm{n}=3), * * * p<0.001$. E. Real-time PCR analysis of CYLD mRNA expression in A549 sublines pTRE and Tet-On Rig-G. The cells were respectively cultured in the presence or absence of Dox $(2 \mu \mathrm{g} / \mathrm{mL})$. The results are expressed as the mean $\pm \operatorname{SEM}(\mathrm{n}=5), * * * p<0.001$. F. NF- $\kappa B$ activity $($ ELISA assay) in A549 sublines pTRE and Tet-On Rig-G treated with siCYLD or siNC (negative control). The results are expressed as the mean \pm $\operatorname{SEM}(\mathrm{n}=3), * * * p<0.001$. 
appears to be an important factor for antitumor activity as only lung cancer cell growth during Rig-G overexpression showed a low rate.

The collaboration and crosstalk of STAT3 and $\mathrm{NF}-\kappa \mathrm{B}$ play pivotal roles in the pathogenesis of various cancers [12,13]. There are several interactions and forms of crosstalk between NF- $\kappa \mathrm{B}$ and STAT3: (1) NF$\kappa \mathrm{B}$ physically interacts with STAT3 $[16,29]$; (2) these factors cooperate with gene promoters/enhancers [30]; (3) the cooperation of STAT3 and NF- $\mathrm{KB}$ builds a positive feedback loop in its activation process [17]. In lung cancer, constitutively activated STAT3 has been observed in neoplastic cells [31-33]. In our case, we have provided evidence that the inhibition of lung cancer growth of the overexpressing Rig-G line was blocked by the transgenic expression of STAT3, indicating that the function of
Rig-G in tumor inhibition involves STAT3. MiR21 and miR181b-1 are important STAT3 effectors whose ablation in A549 cells results in decreased tumor growth [17]. Here, we demonstrate that specific Rig-G overexpression in lung cancer cells interferes with the expression of STAT3, miR21, and miR181b-1. A study conducted by IIiopoulos et al. suggested a mechanism in which STAT3 activation of MiR21 and miR181b-1 is required to activate the NF- $\kappa \mathrm{B}$ pathway via PTEN/Akt and CYLD in an ER-Src model of oncogenesis [17]. In the current study, Rig-G inhibits NF- $\kappa$ B activity by increasing PTEN expression in lung cancer cells. In turn, Rig-G activated CYLD by inhibiting miR181b-1, and subsequently, NF$\kappa \mathrm{B}$. Additionally, NF- $\kappa \mathrm{B}$ inhibition resulted in a decreased induction of IL-6, which is an important STAT3 activator that promotes tumor development and growth in colon
A
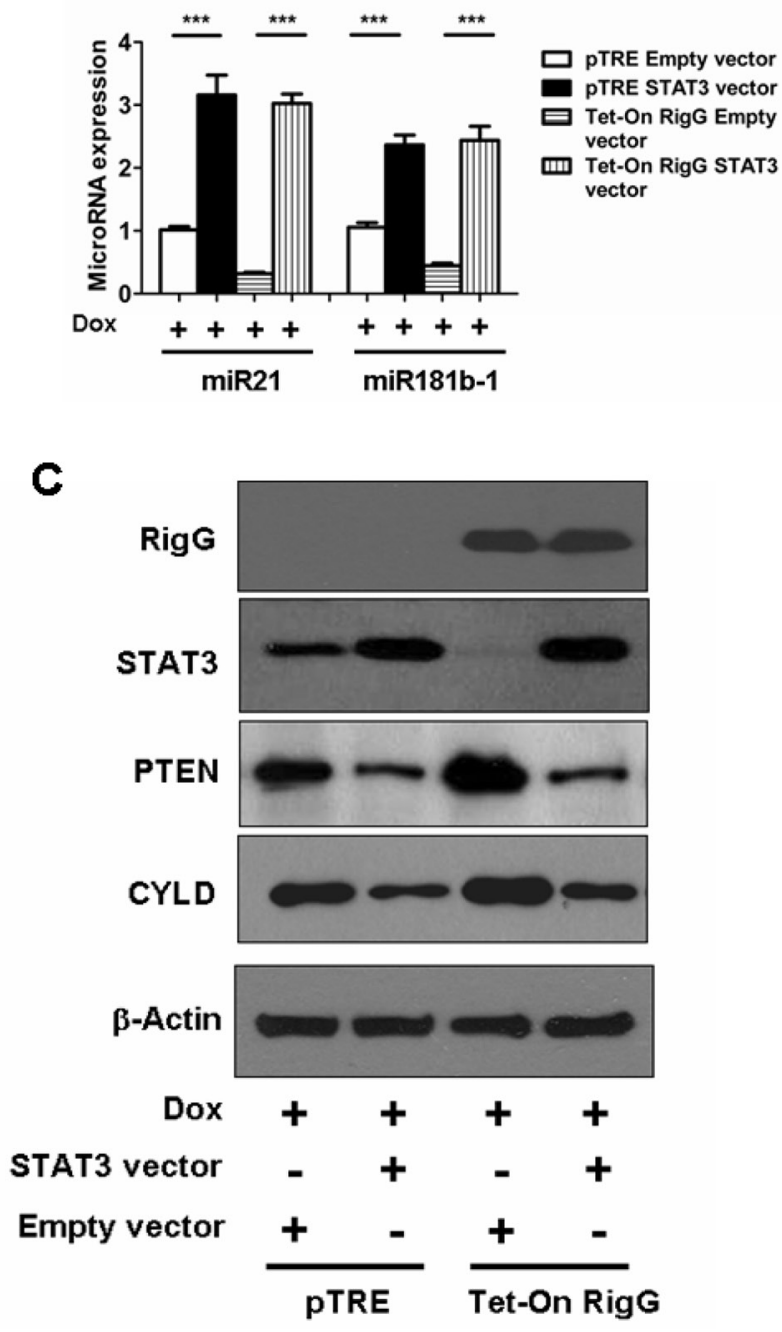

B

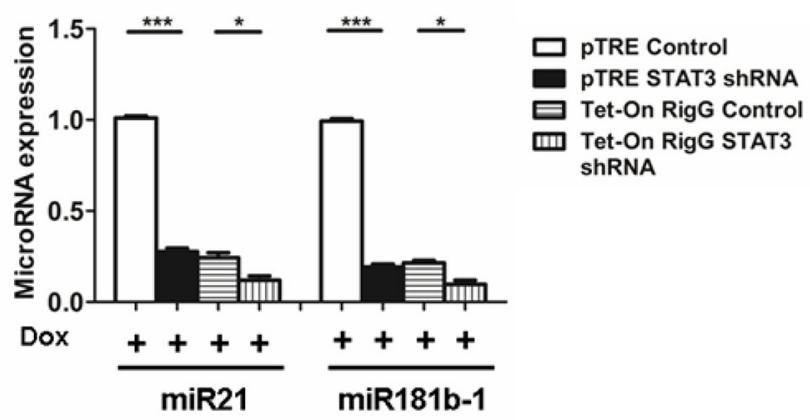

D

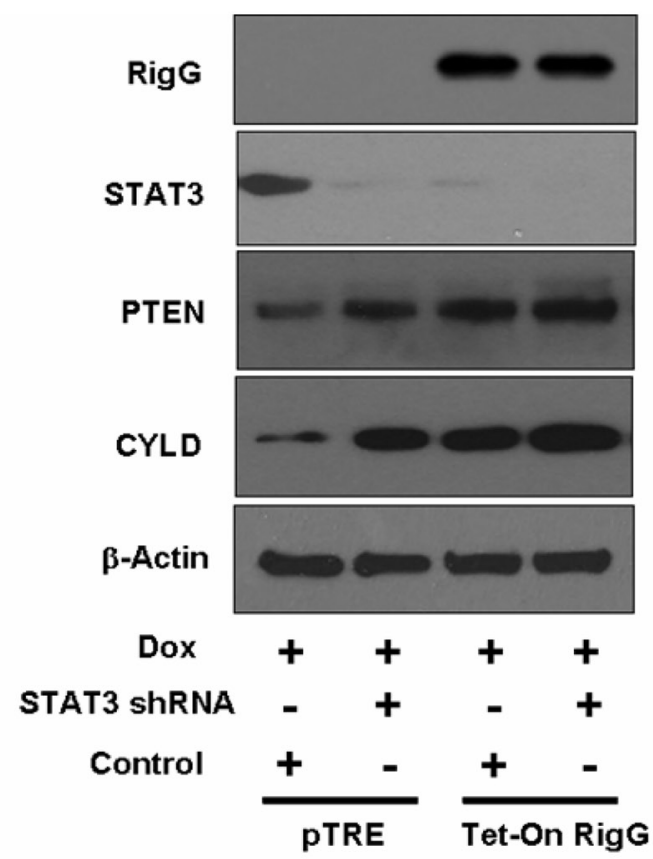

Figure 12: Rig-G downregulates MiR21/PTEN and miR181b-1/CYLD pathways through STAT3. A and B. MiR181b-1 and miR21 expression levels were analyzed in A549 sublines pTRE and Tet-On Rig-G respectively transfected with indicated expression plasmids (A) or shRNA plasmids (B). The cells were cultured in the presence of Dox $(2 \mu \mathrm{g} / \mathrm{mL})$. The results are expressed as the mean \pm SEM $(\mathrm{n}=5),{ }^{* * *} p<0.001$. (B) A549 sublines pTRE and Tet-On Rig-G respectively transfected with indicated expression plasmids C. or shRNA plasmids $\mathbf{D}$. were analyzed for the expression of the indicated proteins by immunoblot analysis. 
cancer and lung cancer [34]. Thus, the overexpression of Rig-G in lung cancer cells builds a negative feedback loop during the development of tumor growth inhibition effect.

In conclusion, the results of the present study show that Rig-G inhibits lung cancer cell growth via MiR21/ PTEN/Akt and miR181b-1/CYLD-dependent inhibition of NF- $\kappa \mathrm{B}$, which is associated with decreased STAT3 activity. Our findings contribute to a better understanding of the antitumor effect mechanism of Rig-G, as well as offer a novel strategy for lung cancer therapy.

\section{MATERIALS AND METHODS}

\section{Cell culture}

Human NSCLC cell lines A549, H1792, and Calu1 (all three from ATCC) were cultured in Dulbeccos's modified Eagle's medium (DMEM) (Hyclone Laboratories, Inc., South, UT, USA) supplemented with $10 \%$ fetal calf serum (FCS) (Invitrogen, Grand Island, NY, USA), $100 \mathrm{U} / \mathrm{mL}$ penicillin and $100 \mathrm{U} / \mathrm{mL}$ streptomycin (Hyclone Laboratories., Inc.). Cell cultures were performed at $37^{\circ} \mathrm{C}$ in humidified air with $5 \% \mathrm{CO}_{2}$. ATRA ( $1 \mu \mathrm{M}$, Sigma-Aldrich, St. Louis, MO, USA) was applied to the cells for $96 \mathrm{~h}$.

\section{Transfection and establishment of lung cancer Tet-On-Rig-G stable transformants}

Rig-G cDNA (1.5 kb in size) was constructed in an expression vector pTRE by using the Tet-On system (Clontech Laboratories, Mountain View, CA, USA) as described elsewhere [8]. The lung cancer TetOn cells (A549, H1792, and Calu-1 cells) were stably transfected with a pTet-On regulatory vector by using an electroporation method. Positive clones were selected by $800 \mu \mathrm{g} / \mathrm{mL}$ G418 (Clontech Laboratories). After establishing the lung cancer Tet-On stable cells, these were transfected again with pTRE-Rig-G. Electroporation was performed using a Gene-Pulser (Bio-Rad) at $280 \mathrm{~V}$ and $960 \mathrm{mF}$ in 0.4-cm cuvettes (Bio-Rad, Hercules, CA, USA). Individual positive clones were then isolated in the growth medium (containing $200 \mu \mathrm{g} / \mathrm{mL}$ hygromycin B) via limiting dilution analysis in 96-well plates. In the presence of Dox ( $2 \mu \mathrm{g} / \mathrm{mL}$, Sigma-Aldrich) for $24 \mathrm{~h}$, the lung cancer Tet-On-Rig-G cell lines (A549 Tet-On-Rig-G, H1792 TetOn-Rig-G, and Calu-1 Tet-On-Rig-G) expressed Rig-G. An empty vector pTRE was used as a control. For TNF $\alpha$ (Invitrogen) stimulation, after DOX treatment for $24 \mathrm{~h}$, Tet-On-Rig-G cells and pTRE cells were treated with 1 $\mathrm{ng} / \mathrm{mL} \mathrm{TNF} \alpha$ for $1 \mathrm{~h}$. For establishment of the STAT3 expression or knockdown stable cell line, A549 TetOn-Rig-G cells, and A549 pTRE, cells were transfected with STAT3 plasmids, STAT3 shRNA plasmids or empty vectors (all from OriGene Technologies, Inc. Rockville, MD, USA), respectively, by electroporation.
Individual stable cells were selected under $800 \mu \mathrm{g} / \mathrm{mL}$ G418 (Clontech Laboratories) or $5 \mu \mathrm{g} / \mathrm{mL}$ puromycin (Invitrogen). RNA interference (RNAi) plasmids Rig-G were constructed with the following sequences for the Rig-G: 5'-CACCGACAATCCCATCAGCGC TACTT CAAGAGAGTAGCGCTGATGGGATTG-3' and 5'-AAA ACAATCCCATC AGCGCTACTCTCTTGAAGTAGC GCTGATGGGATTGTC-3'. Puromycin was added at a concentration of $5 \mu \mathrm{g} / \mathrm{ml}$. NF- $\kappa \mathrm{B}$ p 65 RNAi plasmids were described [24].

\section{Western blot analysis}

Western blot analysis was performed as described elsewhere [35]. Briefly, 30mg total protein or $5 \mathrm{mg}$ nuclear protein were loaded on $10 \%$ SDS polyacrylamide gels, electrophoresed, and blotted onto Hybond-C Extra membranes (Amersham Bioscience, Buckinghamshire, UK). Primary antibodies used for western blot analysis included the following: rabbit anti Rig-G (a gift from Dr. Jianhua Tong [7]), mouse anticyclin D1, mouse anti-PCNA, mouse anti-p21, mouse anti-STAT3, rabbit anti- Stat3 (pTyr705) rabbit antic-myc, rabbit anti-Akt (pSer473), rabbit anti-PTEN, rabbit anti- I $\kappa \mathrm{B} \alpha$, rabbit anti-CYLD, rabbit anti-Bcl-2 (all eleven from Cell Signaling Technology), mouse anti-ubiquitin, rabbit anti-p27, rabbit anti-p65, rabbit anti-LaminB (all four from Santa Cruz Biotechnology, Santa Cruz, CA, USA), rabbit anti-VEGF (from Abcam, Cambridge, UK), and mouse anti- $\beta$-actin (Sigma Aldrich). HRP-conjugated goat anti-rabbit (Santa Cruz) or rabbit anti-mouse (Dako, Carpinteria, CA, USA) was used as secondary antibody.

For co-immunoprecipitation, cells were incubated

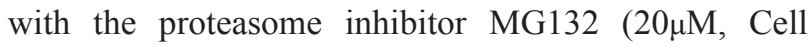
Signaling Technology) for 5h. Protein extracts were prepared in a buffer containing $150 \mathrm{mM} \mathrm{NaCl}, 50 \mathrm{mM}$ Tris- $\mathrm{HCl}$ ( $\mathrm{pH} \mathrm{8.0),} \mathrm{and} \mathrm{0.5 \%} \mathrm{Non-idet} \mathrm{P-40,} \mathrm{and} \mathrm{then}$ mixed with protein A-agarose (Santa Cruz Biotechnology) and rabbit anti-I $\kappa \mathrm{B} \alpha$ at $4^{\circ} \mathrm{C}$ overnight with continuous rotation. The precipitated proteins were eluted by boiling beads in an SDS-loading buffer and analyzed by western blotting.

\section{RNA isolation and real-time PCR analysis}

Total RNAs were isolated from cells using an RNeasy plus mini kit (Qiagen, Santa Clarita, CA, USA), following the manufacturer's recommendations. Real-time PCR reaction mixtures have been previously described [36]. Briefly, cDNA was synthesized by reverse transcription using a First-Strand cDNA Synthesis kit (Invitrogen). Real-time PCR was performed using the QPCR SYBR Green Mix (BioRad) on an AB 7300 Real time PCR system machine (AB Applied Biosystems, Singapore). The following 
PCR primers were used: $\beta$-actin, 5'-AGCCTCGCCTTT GCCGA-3' and 5'-CTGGTGCCTGGGGCG-3'; Rig-G, 5'-GAAGAAATGAAAGG GCGAAGG-3' and 5'-AGG ACATCTGTTTGGCAAGGAG-3'; STAT3, 5'-CCAG TCAGTGACCAGGCAGAAG-3' and 5'-GCACGTACT CCATCGCTGACA-3'; CYLD, 5'-TCTATGGGGTAATC CGTTGG-3' and 5' - CAGCCTGCACACTCATCT TC3'; TNF $\alpha$, 5'-CCCAGGCAGTCAGATCATCTTC-3' and 5'-AGCTGCCCCTCA GCTTGA-3'; IL-6, 5'-TCAC CAGGCAAGTCTCCTCATTG -3 ' and 5'-ACTC CTTC TCCACAAGCGCCTT-3'; IL-1 $\beta$, 5'-TCTGA ATTCTATGGCAGAAGTACCTGA GC-3' and 5'-TTC GGATCCGGAAGACACAAATTGC-3'; miR-181b-1, 5'-ACACT CCAGCTGGGAACATTCATTGCTGTC GG-3' and 5'- CTCAACTGGTGTCGTGG A-3'; miR21, 5'-GCCGCTAGCTTATCAGACTGATGT-3' and 5'-GTGCAGGGTC CGAGGT-3'. Specificity of RT-PCR was controlled by 'no reverse transcription' controls and melting curve analysis. Quantitative PCR results were obtained using the DDCT (cycle threshold) method. Data were normalized to the $\beta$-actin levels in each sample.

\section{BrdU ELISA cell proliferation assay}

Lung cancer cell proliferation was determined using a commercially available cell proliferation ELISA, BrdU (colorimetric) kit (Roche, Mannheim, Germany), as previously described [35]. For ATRA stimulation, the cells were stimulated with $1 \mu \mathrm{M}$ ATRA for $96 \mathrm{~h}$. For Rig-G overexpression, after 5 days of Dox treatment, tumor cell supernatants were aspirated, and growth media that contained $10 \mu \mathrm{M}$ BrdU was added. Tumor cells were incubated for an additional $2 \mathrm{~h}$ at $37^{\circ} \mathrm{C}$, after which the rate of cell proliferation was measured.

\section{Anchorage-independent colony formation assay}

A colony formation assay was performed as described elsewhere [35]. Briefly, a bottom layer consisting of $0.5 \%$ (w/v) agar in $0.8 \mathrm{~mL}$ of DMEM supplemented with $10 \%$ $(\mathrm{v} / \mathrm{v})$ FBS was first allowed to solidify in each well. Cell lines were suspended in $0.6 \mathrm{~mL} 0.3 \%(\mathrm{w} / \mathrm{v})$ agar containing $10 \%(\mathrm{v} / \mathrm{v})$ FBS and plated onto the bottom layer. ATRA $(1 \mu \mathrm{M})$ or Dox $(2 \mu \mathrm{g} / \mathrm{mL})$ were used at the indicated concentrations in the media. Colony forming efficiency was determined 2 to 3 weeks after plating and cultivation in a humidified $5 \% \mathrm{CO} 2$ atmosphere at $37^{\circ} \mathrm{C}$. The colonies were visualized after staining with $0.005 \%$ crystal violet.

\section{Tumor xenograft models}

Female BALB/c-nu/nu mice were obtained from the National Rodent Laboratory Animal Resource (Shanghai Branch, PRC) and maintained at the pathogen-free Central Animal Facility of the Tongji Hospital of Tongji University. This study was conducted in strict accordance with the recommendations depicted in the Guidelines for the Care and Use of Laboratory Animals of the National Institutes of Health in Bethesda, MD, USA. All animal experiments were approved by the Tongji Hospital of Tongji University Ethics Committee on the Use and Care of Animals. All surgery was performed under sodium pentobarbital anesthesia, and all efforts were made to minimize suffering.

A549 Tet-On-Rig-G cells or A549 pTRE cells (density: $1 \times 10^{6}$ ) were injected subcutaneously in the right flank of nude mice. Tumor growth was monitored every 5 days, and tumor volumes were calculated by using the equation: $\mathrm{V}\left(\mathrm{mm}^{3}\right)=\mathrm{a} \times \mathrm{b}^{2} / 2$, where $\mathrm{a}$ is the largest diameter and $\mathrm{b}$ is the perpendicular diameter [15]. When the tumors reached a size of $70 \mathrm{~mm}^{3}$, mice were fed Dox ( $1 \mu \mathrm{g} / \mathrm{mL}$ mixed in drinking water) or water to regulate Rig-G expression in mice xenografts. At the end of the experiments (40 days), the mice were euthanized, and tumors were resected and fixed in $3.7 \%$ buffered formalin.

\section{Immunohistochemical analyses}

Immunohistochemistry was performed as described elsewhere [37]. The following primary antibodies were used for immunohistochemical analysis: mouse anti-Ki-67 (Abcam, Cambridge, UK) and rabbit anti Rig-G (a gift from Dr. Jianhua Tong [7]). Secondary antibody incubation and staining were performed using the EnVision $\AA+$ System-HRP (DAB) kit (Dako), according to the manufacturer's recommendations. TUNEL staining was performed using the DeadEnd Colorimetric TUNEL System kit (Promega, Madison, WI, USA). The number of Ki-67positive tumor cells and the total number of tumor cells were counted in six microscopic fields of a randomly selected tumor, and the mean value was calculated as the percentage of Ki-67-positive tumor cells.

\section{mRNA expression array}

Total RNA was isolated from A549 Tet-OnRig-G cells or A549 pTRE cells using an RNeasy Mini kit (Qiagen, Hilden, Germany) according to the manufacturer's recommendation. Total mRNA was labeled with Cy5 and then hybridized to Human Whole Genome OneArray ${ }^{\mathrm{TM}}$ Version 6.1 (Phalanx Biotech Group, Xinzhu, Taiwan), scanned with an Axon 4000 scanner (Molecular Devices, Sunnyvale, CA, USA). Spot quantification was done with the use of genepix 4.1 software. Hierarchical clustering of the expression profiles was analyzed by Cluster 3.0 (Molecular Devices). For each group, three samples were analyzed. Differentially expressed genes with fold changes of $>2.0$ were applied to pathway enrichment analysis. GSEA were performed for all KEGG [37] using the GeneTrail server [38]. 


\section{ELISA assay for NF- $\kappa B$ activation}

$\mathrm{NF}-\kappa \mathrm{B}$ activation in cells were analyzed by using TransAM ${ }^{\circledR}$ NF- $\kappa B / p 65$ ELISA kits (Active motif, Carlsbad, CA, USA), according to the manufacturer's instructions. For PTEN inhibition, PTEN inhibitor bpV(phen) (Cell Signaling Technology, Danvers, MA, USA) was added at a concentration of $10 \mu \mathrm{M}$. For microRNA stimulation, A549 Tet-On-Rig-G cells or A549 pTRE cells were treated with $100 \mu \mathrm{M}$ of microRNAs (miR21 or miR181b-1) for $24 \mathrm{~h}$, whereupon Dox $(2 \mu \mathrm{g} /$ $\mathrm{mL}$ ) was added and NF- $\mathrm{kB}$ activation was assessed $24 \mathrm{~h}$ later (total time: $48 \mathrm{~h}$ ).

\section{siRNA experiments}

A549 Tet-On-Rig-G cells or A549 pTRE cells were transfected with siRNAs $(100 \mathrm{nM})$ from Ambion (Austin, TX, USA) against CYLD using siPORT NeoFX transfection agent (Invitrogen). Approximately $100 \mathrm{nM}$ of siRNA (Ambion Inc.) was used as control. Approximately $24 \mathrm{~h}$ after transfection, the resulting cells were treated with Dox $(2 \mathrm{mg} / \mathrm{mL})$, and NF- $\mathrm{kB}$ activation was assessed $24 \mathrm{~h}$ later (total time: $48 \mathrm{~h}$ ).

\section{Luciferase reporter assay}

The NF-кB luciferase adenovirus plasmid pNF$\kappa B-L u c$ (Clontech) containing multiple copies of the $\mathrm{NF}-\kappa \mathrm{B}$ consensus sequence was used to monitor NF- $\kappa \mathrm{B}$ activation [39]. A549 Tet-On-Rig-G cells or A549 pTRE cells were infected with a luciferase adenovirus plasmid pNF-kB-Luc. After $24 \mathrm{~h}$ of incubation, the infected cells were treated with Dox $(2 \mu \mathrm{g} / \mathrm{mL})$ for $24 \mathrm{~h}$, and then subsequently stimulated with TNF $\alpha(1 \mu \mathrm{g} / \mu \mathrm{L})$ for $1 \mathrm{~h}$ and then lysed, and luciferase reporter gene activity was determined by using the luciferase reporter assay kit (Promega, Madison, WI, USA).

\section{Immunofluorescence staining}

The intracellular localization of proteins was analyzed directly on culture coverslips. The adherent cells grown on coverslips were washed in PBS and fixed in methanol at $-20^{\circ} \mathrm{C}$ for $10 \mathrm{~min}$, then washed in PBS. After drying overnight, the cells were fixed in acetone at $4{ }^{\circ} \mathrm{C}$ for $10 \mathrm{~min}$ and air-dried. The indicated primary antibodies were diluted in PBS and incubated with the permeabilized cells for 1-2 $\mathrm{h}$. Subsequently, secondary antibodies, including Alexa Fluor ${ }^{\circledR}$ 488-conjugated anti-rabbit and Alexa Fluor ${ }^{\circledR}$ 594-conjugated anti-rabbit antibody (Cell Signaling Technology), were incubated with cells for $1 \mathrm{~h}$. All incubations were carried out at room temperature and followed by three washes in PBS. Finally, the slides were mounted with $5 \mu$ mounting medium containing DAPI (Vector Laboratories, Burlingame, CA) and examined by microscopy
(Olympus BX60, Japan) with CCD camera (Model 4.2, Diagnostic, USA).

\section{Electrophoretic mobility shift assay (EMSA)}

EMSA were performed using the LightShift Chemiluminescent EMSA Kit (Thermo Scientific, Rockford, Ll, USA). Briefly, nuclear proteins were isolated from lung tumor cells using Nuclear Extract Kit (Active Motif, Carlsbad, CA, USA) and NF- $\kappa B$ DNA binding activity was measured by EMSA. Nuclear proteins were incubated with biotin-labeled doublestranded NF- $\mathrm{KB}$ consensus probe at room temperature for $30 \mathrm{~min}$. DNA-protein complexes were resolved on a $5 \%$ nondenaturing polyacrylamide gel prepared in $45 \mathrm{mM}$ Tris-borate and $1 \mathrm{mM}$ EDTA (TBE) buffer. The specimens were electrotransferred onto a $0.4-\mu \mathrm{m}$ Biodyne B nylon membrane (Thermo Scientific) at 380 $\mathrm{mA}$ for 30 min at $4{ }^{\circ} \mathrm{C}$. The membrane was UV crosslinked and binding activity of NF- $\kappa B$ to the probe was determined using a chemiluminescent EMSA kit. For EMSA supershift experiments, nuclear extract were incubated for $30 \mathrm{~min}$ at room temperature with $2 \mathrm{mg}$ of rabbit anti-p65 antibody (Santa Cruz) before addition of labeled oligonucleotides.

\section{Statistical analysis}

Data are expressed as the mean \pm SEM. Comparisons between groups were analyzed by using the $t$-test (twosided). A P value of $<0.05$ was considered statistically significant.

\section{ACKNOWLEDGMENTS}

This work was supported by National Natural Science Foundation of China Grants (81272603; 81472179), Shanghai Pujiang Program (13PJ1407300) and Shanghai Shenkang Program (SHDC22014008) to Dong Li. We thank Dr. Jianhua Tong for Rig-G antibody support.

\section{CONFLICTS OF INTEREST}

The authors have declared that no conflicts of interest exist.

\section{REFERENCES}

1. Aberle DR, Adams AM, Berg CD, Black WC, Clapp JD, Fagerstrom RM, Gareen IF, Gatsonis C, Marcus PM, Sicks JD. Reduced lung-cancer mortality with low-dose computed tomographic screening. N Engl J Med. 2011; 365: 395-409.

2. Takahashi H, Ogata H, Nishigaki R, Broide D H, Karin M. Tobacco smoke promotes lung tumorigenesis by triggering IKKbeta- and JNK1-dependent inflammation. Cancer Cell. 2010; 17: 89-97. 
3. Dasgupta P, Kinkade R, Joshi B, Decook C, Haura E, Chellappan S. Nicotine inhibits apoptosis induced by chemotherapeutic drugs by up-regulating XIAP and survivin. Proc Natl Acad Sci U S A. 2006; 103:6332-6337.

4. Siegel RL, Miller KD, Jemal A. Cancer statistics, 2015. CA Cancer J Clin. 2015; 65: 5-29.

5. Herbst RS, Heymach JV, Lippman SM. Lung cancer. N Engl J Med. 2008; 359: 1367-1380.

6. Yu M, Tong JH, Mao M, Kan LX, Liu MM, Sun YW, Fu G, Jing YK, Yu L, Lepaslier D, Lanotte M, Wang ZY, Chen Z, et al. Cloning of a gene (RIG-G) associated with retinoic acid-induced differentiation of acute promyelocytic leukemia cells and representing a new member of a family of interferon-stimulated genes. Proc Natl Acad Sci U S A. 1997; 94: 7406-7411.

7. Xu GP, Zhang ZL, Xiao S, Zhuang LK, Xia D, Zou QP, Jia PM, Tong JH. Rig-G negatively regulates SCF-E3 ligase activities by disrupting the assembly of COP9 signalosome complex. Biochem Biophys Res Commun. 2013; 432: 425-430.

8. Xiao S, Li D, Zhu HQ, Song MG, Pan XR, Jia PM, Peng LL, Dou AX, Chen GQ, Chen SJ, Chen Z, Tong JH. RIG-G as a key mediator of the antiproliferative activity of interferon-related pathways through enhancing p21 and p27 proteins. Proc Natl Acad Sci U S A. 2006; 103: 16448-16453.

9. Shalapour S, Karin M. Immunity, inflammation, and cancer: an eternal fight between good and evil. J Clin Invest. 2015; 125: 3347-3355.

10. DiDonato JA, Mercurio F, Karin M. NF-kappaB and the link between inflammation and cancer. Immunol Rev. 2012; 246: 379-400.

11. He G, Karin M. NF- $\kappa$ B and STAT3 - key players in liver inflammation and cancer. Cell Res. 2011; 21: 159-168.

12. Fan Y, Mao R, Yang J. NF-kappaB and STAT3 signaling pathways collaboratively link inflammation to cancer. Protein Cell. 2013; 4: 176-185.

13. Grivennikov SI, Greten FR, Karin M. Immunity, inflammation, and cancer. Cell. 2010; 140: 883-899.

14. Grivennikov SI, Karin M. Inflammation and oncogenesis: a vicious connection. Curr Opin Genet Dev. 2010; 20: 65-71.

15. Terlizzi M, Casolaro V, Pinto A and Sorrentino R. Inflammasome: cancer's friend or foe? Pharmacol Ther. 2014; 143: 24-33.

16. Grivennikov SI, Karin M. Dangerous liaisons: STAT3 and NF-kappaB collaboration and crosstalk in cancer. Cytokine Growth Factor Rev. 2010; 21: 11-19.

17. Iliopoulos D, Jaeger SA, Hirsch HA, Bulyk ML, Struhl K. STAT3 activation of miR-21 and miR-181b-1 via PTEN and CYLD are part of the epigenetic switch linking inflammation to cancer. Mol Cell. 2010; 39: 493-506.
18. Kim HJ, Lotan R. Identification of retinoid-modulated proteins in squamous carcinoma cells using high-throughput immunoblotting. Cancer Res. 2004; 64: 2439-2448.

19. Vlahopoulos SA, Cen O, Hengen N, Agan J, Moschovi M, Critselis E, Adamaki M, Bacopoulou F, Copland JA, Boldogh I, Karin M, Chrousos GP. Dynamic aberrant NF-kappaB spurs tumorigenesis: a new model encompassing the microenvironment. Cytokine Growth Factor Rev. 2015; 26: 389-403.

20. Grivennikov, SI, Karin M. Inflammatory cytokines in cancer: tumour necrosis factor and interleukin 6 take the stage. Ann Rheum Dis. 2011; 70 Suppl 1: i104-i108.

21. Lou YJ, Pan XR, Jia PM, Li D, Xiao S, Zhang ZL, Chen SJ, Chen Z, Tong JH. IRF-9/STAT2 [corrected] functional interaction drives retinoic acid-induced gene $\mathrm{G}$ expression independently of STAT1. Cancer Res. 2009; 69: 3673-3680.

22. Lou YJ, Zhang ZL, Pan XR, Xu GP, Jia PM, Li D, Tong JH. Intact JAK-STAT signaling pathway is a prerequisite for STAT1 to reinforce the expression of RIG-G gene. Exp Cell Res. 2011; 317: 513-520.

23. Gu ZM, Liu CX, Wu SF, Zhao M, Xu HZ, Liu W, Zhou HC, Chen GQ, Wu YL. PU.1 directly regulates retinoic acidinduced expression of RIG-G in leukemia cells. FEBS Lett. 2011; 585: 375-380.

24. Li D, Beisswenger C, Herr C, Hellberg J, Han G, Zakharkina T, Voss M, Wiewrodt R, Bohle RM, Menger MD, Schmid RM, Stöckel D, Lenhof HP, et al. Myeloid cell RelA/p65 promotes lung cancer proliferation through Wnt/ beta-catenin signaling in murine and human tumor cells. Oncogene. 2014; 33: 1239-1248.

25. Li D, Beisswenger C, Herr C, Schmid RM, Gallo RL, Han G, Zakharkina T, Bals R. Expression of the antimicrobial peptide cathelicidin in myeloid cells is required for lung tumor growth. Oncogene. 2014; 33: 2709-2716.

26. Ben-Neriah Y, Karin M. Inflammation meets cancer, with NF-kappaB as the matchmaker. Nat. Immunol. 2011; 12: 715-723.

27. Xia Y, Shen S, Verma IM. NF-kappaB, an active player in human cancers. Cancer Immunol Res. 2014; 2: 823-830.

28. Takahashi H, Ogata H, Nishigaki R, Broide DH, Karin M. Tobacco smoke promotes lung tumorigenesis by triggering IKKbeta- and JNK1-dependent inflammation. Cancer Cell. 2010; 17: 89-97.

29. Yang J, Liao X, Agarwal MK, Barnes L, Auron PE, Stark GR. Unphosphorylated STAT3 accumulates in response to IL-6 and activates transcription by binding to NFkappaB. Genes Dev. 2007; 21: 1396-1408.

30. Snyder M, Huang J, Huang XY, Zhang JJ. A signal transducer and activator of transcription 3.Nuclear Factor kappaB (Stat3.NFkappaB) complex is necessary for the expression of fascin in metastatic breast cancer cells in response to interleukin (IL)-6 and tumor necrosis factor (TNF)-alpha. J Biol Chem. 2014; 289: 30082-30089. 
31. Schutz A, Roser K, Klitzsch J, Lieder F, Aberger F, Gruber W, Mueller KM, Pupyshev A, Moriggl R, Friedrich K. Lung Adenocarcinomas and Lung Cancer Cell Lines Show Association of MMP-1 Expression with STAT3 Activation. Transl Oncol. 2015; 8: 97-105.

32. Errico A. Lung cancer: Driver-mutation-dependent stratification: learning from STAT3. Nat Rev Clin Oncol. 2015; $12: 251$.

33. Grabner B, Schramek D, Mueller KM, Moll HP, Svinka J, Hoffmann T, Bauer E, Blaas L, Hruschka N, Zboray K, Stiedl P, Nivarthi H, Bogner E, et al. Disruption of STAT3 signalling promotes KRAS-induced lung tumorigenesis. Nat Commun. 2015; 6: 6285.

34. Qu Z, Sun F, Zhou J, Li L, Shapiro SD, Xiao G. Interleukin-6 Prevents the Initiation but Enhances the Progression of Lung Cancer. Cancer Res. 2015; 75: 3209-3215.

35. Li D, Liu W, Wang X, Wu J, Quan W, Yao Y, Bals R, Ji $\mathrm{S}$, Wu K, Guo J, Wan H. Cathelicidin, an antimicrobial peptide produced by macrophages, promotes colon cancer by activating the Wnt/beta-catenin pathway. Oncotarget. 2015; 6: 2939-2950. doi: 10.18632/oncotarget.2845.

36. Li D, Wang X, Wu JL, Quan WQ, Ma L, Yang F, Wu KY, Wan HY. Tumor-produced versican V1 enhances hCAP18/ LL-37 expression in macrophages through activation of TLR2 and vitamin D3 signaling to promote ovarian cancer progression in vitro. PLoS One. 2013; 8: e56616.

37. Kanehisa M, Goto S, Furumichi M, Tanabe M, Hirakawa M. KEGG for representation and analysis of molecular networks involving diseases and drugs. Nucleic Acids Res. 2010; 38: D355-D360.

38. Backes C, Keller A, Kuentzer J, Kneissl B, Comtesse N, Elnakady YA, Müller R, Meese E, Lenhof HP. GeneTrail-advanced gene set enrichment analysis. Nucleic Acids Res. 2007; 35: W186-W192.

39. Wang X, Jiang CM, Wan HY, Wu JL, Quan WQ, Bals $\mathrm{R}, \mathrm{Wu} \mathrm{KY}$, Li D. CDA-2, a urinary preparation, inhibits lung cancer development through the suppression of NF-kappaB activation in myeloid cell. PLoS One. 2012; 7: e52117. 